\title{
TRES LECTURAS DE LA BUENA FE PROCESAL ${ }^{*}$
}

\section{THREE READINGS OF PROCEDURAL GOOD FAITH}

\section{TROIS LECTURES DE BONNE FOI PROCÉDURALE}

Jorge Larroucau Torres"

\section{RESUMEN}

La buena fe es una pieza clave en la justicia. En este trabajo se bosquejan tres modos conceptualmente diversos de comprender la buena fe procesal en la litigación moderna: una tesis fuerte (contribuir a la justicia del caso), una tesis mínima (no litigar con dolo) y una tesis más que mínima (cumplir con ciertos deberes de colaboración y con las cargas procesales). Cada una de estas tesis entraña consecuencias disímiles para las partes, los terceros y para el propio juez. En este análisis se demuestra que la buena fe procesal entendida como un umbral más que mínimo es la que mejor se adapta a una litigación en que deben equilibrarse intereses privados y públicos. La determinación de cuál es el mejor reparto de las cargas y los deberes en cada clase de juicio es una tarea prioritaria (aunque no exclusiva) de la literatura procesal.

Palabras claves: buena fe procesal, deberes y cargas, dolo, justicia.

* Este trabajo fue discutido en un Seminario 3 que tuvo lugar a fines de mayo en la Facultad de Derecho de la Universidad Alberto Hurtado, con la participación de Francesco Carretta y de Felipe Gorigoitía. Doy las gracias a Francesco y a Felipe por las sugerentes observaciones que hicieron a todo el texto. También le agradezco al Colegio de Abogados de Antofagasta por su amable invitación a exponer este trabajo ante un atento auditorio de abogados, a mediados de junio de 2013. Este artículo es parte de una investigación financiada a través de un proyecto FONDECYT iniciación $\mathrm{N}^{\circ}$ 11121293: Los estándares de prueba en la justicia civil patrimonial, cuyo apoyo reconozco en esta nota.

** Profesor de Derecho Civil y de Derecho Procesal Civil, Universidad Alberto Hurtado. Correo: jlarrouc@uahurtado.cl. Dirección postal: Cienfuegos 41, Santiago de Chile. Artículo recibido el 25 de junio de 2013 y aceptado para su publicación el 8 de agosto de 2013. 


\begin{abstract}
Good faith is a key part in the justice. This paper outlines three conceptually different ways to understand the procedural good faith in modern litigation: a strong thesis (to contribute to the justice of the case), a minimal thesis (not to litigate with malice) and a more than minimal thesis (to fulfill with certain duties of collaboration and procedural burdens). Each approach entails dissimilar implications for the parties, third parties and the court itself. This analysis demonstrates that good faith understood as a more than minimal threshold is the one that is best suited to a process where private and public interests must be balanced. To establish the best distribution of the burdens and duties in the litigation is a priority (but not exclusive) task in the procedural literature.
\end{abstract}

Key words: Procedural good faith, Duties and burdens, Malice, Justice.

\title{
RÉSUMÉ
}

La bonne foi est une pièce maîtresse de la justice. Cet article ébauche de trois façons différentes sur le plan conceptuel de comprendre la bonne foi procédurale dans les litiges modernes : une thèse forte (contribuer à la justice du cas concret), une thèse minimale (ne pas poursuivre de façon préméditée) et une thèse plus que minimale (accomplir certains devoirs de collaboration et vis-à-vis des charges de la procédure). Chacune de ces thèses a des conséquences variables pour les parties, les tiers et le juge lui-même. Cette analyse démontre que la bonne foi procédurale conçue comme un seuil plus que minimal est celle qui s'adapte le mieux à une action en justice dans laquelle il faut équilibrer les intérêts privés et les intérêts publics. La détermination sur la répartition optimale des charges et des devoirs dans chaque type de procès est une tâche prioritaire (bien que non exclusive) de la littérature procédurale.

Mots clés: Bonne foi procédurale, devoirs et charges, préméditation, Justice.

\section{EL IMPERIO DE LA BUENA FE PROCESAL}

El objetivo de la buena fe procesal es que el interés de las partes no cancele los compromisos que sirve la administración de justicia. Eso es lo que se observa, con fórmulas más o menos diversas, en el Derecho Comparado y especial- 
mente en la justicia civil. Tanto en los procesos civiles de Europa (Alemania ${ }^{1}$, España ${ }^{2}$, Inglaterra ${ }^{3}$, Italia $^{4}$, Portugal, en su versión de $1961^{5}$ y en el Código de Processo Civil vigente a contar de 2013) ${ }^{6}$ como de América (Perú ${ }^{7}$, Uruguay $^{8}$,

${ }^{1} \S 138.1$ Zivilprozessordnung (2002): "Deber de declaración sobre los hechos; deber de decir la verdad. 1) Las partes deben hacer sus declaraciones sobre cuestiones de hecho en forma completa y adecuada a la verdad”. Cfr. $Z P O$, traducción de Juan Carlos Ortiz y Álvaro Pérez Ragone, Konrad Adenauer Stiftung, Programa Estado de Derecho para Sudamérica, Montevideo, 2006.

${ }^{2}$ Art. 247.1 Ley de Enjuiciamiento Civil (2000): "Los intervinientes en todo tipo de procesos deberán ajustarse en sus actuaciones a las reglas de la buena fe".

${ }^{3}$ Rule 1.3 Civil Procedure Rules (1998): "The parties are required to help the court to further the overriding objective", Rule 3.4 (2) (b): "The court may strike out a statement of case if it appears to the court: that the statement of case is an abuse of the court's process or is otherwise likely to obstruct the just disposal of the proceedings".

${ }^{4}$ Art. 88 Codice di Procedura Civile (1942): "Le parti e i loro difensori hanno il dovere di comportarsi in giudizio con lealtà e probità".

${ }^{5}$ Art. 266 Código de Processo Civil (1961/1995-96): "Princípio da cooperação. 1- Na condução e intervenção no processo, devem os magistrados, os mandatários judiciais e as próprias partes cooperar entre si, concorrendo para se obter, com brevidade e eficácia, a justa composição do litígio. 2- O juiz pode, em qualquer altura do processo, ouvir as partes, seus representantes ou mandatários judiciais, convidando-os a fornecer os esclarecimentos sobre a matéria de facto ou de direito que se afigurem pertinentes e dando-se conhecimento à outra parte dos resultados da diligência", art. 266-A: "Dever de boa fé processual. As partes devem agir de boa fé e observar os deveres de cooperação resultantes do preceituado no artigo anterior", art. 456: "Responsabilidade no caso de má fé - Noção de má fé: 1- Tendo litigado de má fé, a parte será condenada em multa e numa indemnização à parte contrária, se esta a pedir. 2 - Diz-se litigante de má fé quem, com dolo ou negligência grave: a) Tiver deduzido pretensão ou oposição cuja falta de fundamento não devia ignorar; b) Tiver alterado a verdade dos factos ou omitido factos relevantes para a decisão da causa; c) Tiver praticado omissão grave do dever de cooperação; d) Tiver feito do processo ou dos meios processuais um uso manifestamente reprovável, com o fim de conseguir um objetivo ilegal, impedir a descoberta da verdade, entorpecer a ação da Justiça ou protelar, sem fundamento sério, o trânsito em julgado da decisão. 3 - Independentemente do valor da causa e da sucumbência, é sempre admitido recurso, em um grau, da decisão que condene por litigância de má fé".

${ }^{6}$ Art. 7 Código de Processo Civil (2013): "Princípio da cooperação. 1- Na condução e intervenção no processo, devem os magistrados, os mandatários judiciais e as próprias partes cooperar entre si, concorrendo para se obter, com brevidade e eficácia, a justa composição do litígio. 2- O juiz pode, em qualquer altura do processo, ouvir as partes, seus representantes ou mandatários judiciais, convidando -os a fornecer os esclarecimentos sobre a matéria de facto ou de direito que se afigurem pertinentes e dando- se conhecimento à outra parte dos resultados da diligência", art. 8: "Dever de boa -fé processual. As partes devem agir de boa -fé e observar os deveres de cooperação resultantes do preceituado no artigo anterior".

${ }^{7}$ Art. 109.1 Código Procesal Civil (1993): "Deberes de las partes, abogados y apoderados. Son deberes de las partes, abogados y apoderados: 1. Proceder con veracidad, probidad, lealtad y buena fe en todos sus actos e intervenciones en el proceso".

${ }^{8}$ Art. 5.1 Código General del Proceso (1989): "Las partes, sus representantes o asistentes $\mathrm{y}$, en general, todos los partícipes del proceso, ajustarán su conducta a la dignidad de la justicia, al respeto que se deben los litigantes y a la lealtad y buena fe". 
Argentina ${ }^{9}$, Brasil $^{10}$, Colombia $^{11}$ y Estados Unidos de Norteamérica ${ }^{12}$, varios de los sistemas jurídicos cuyo desarrollo procesal es destacado contemplan este imperativo de que se actúe de buena fe al litigar. Lo mismo se aprecia en los documentos que promueven una armonización de los procesos judiciales: así, por ejemplo, en los Principios UNIDROIT de $2004^{13}$ y en el aún más cercano Código Procesal Civil Modelo para Iberoamérica de $1988^{14}$.

En términos normativos, entonces, la buena fe procesal es un protagonista indiscutido de la administración de justicia. Ella le brinda al juez una forma legítima de diferenciar entre los comportamientos admisibles y los que merecen una censura en la litigación. Esto alivia hasta cierto punto el trabajo del juez. La solución no es más que relativa porque, como se sabe, ella no se encuentra ajena al enigma de las cláusulas abiertas; esto es, no se escapa a las preguntas acerca de cuáles son sus límites en la práctica, cuál es su núcleo de sentido y hasta dónde se expande su zona de penumbra. Las respuestas a estas dudas requieren de un permanente

${ }^{9}$ Art. 34.5 (d) Código Procesal Civily Comercial de la Nación (1981): "Deberes. Son deberes de los jueces: 5) Dirigir el procedimiento, debiendo, dentro de los límites expresamente establecidos en este Código: d) Prevenir y sancionar todo acto contrario al deber de lealtad, probidad y buena fe".

$262{ }^{10}$ Art. 14.2 Código de Processo Civil (1973): "São deveres das partes e de todos aqueles que de qualquer forma participam do processo: II - proceder com lealdade e boa-fé".

${ }^{11}$ Art. $42 \mathrm{~N}^{\circ} 3$ Código General del Proceso (2012): "Deberes del juez. Son deberes del juez: Prevenir, remediar, sancionar o denunciar por los medios que este código consagra, los actos contrarios a la dignidad de la justicia, lealtad, probidad y buena fe que deben observarse en el proceso, lo mismo que toda tentativa de fraude procesal"; art. $78 \mathrm{~N}^{\circ} 1$ : "Deberes de las partes y sus apoderados. Son deberes de las partes y sus apoderados: Proceder con lealtad y buena fe en todos sus actos".

${ }^{12}$ Rule 11 (b) Federal Rules of Civil Procedure (1938/2007): "Representations to the Court. By presenting to the court a pleading, written motion, or other paper-whether by signing, filing, submitting, or later advocating it-an attorney or unrepresented party certifies that to the best of the person's knowledge, information, and belief, formed after an inquiry reasonable under the circumstances: (1) it is not being presented for any improper purpose, such as to harass, cause unnecessary delay, or needlessly increase the cost of litigation; (2) the claims, defenses, and other legal contentions are warranted by existing law or by a nonfrivolous argument for extending, modifying, or reversing existing law or for establishing new law; (3) the factual contentions have evidentiary support or, if specifically so identified, will likely have evidentiary support after a reasonable opportunity for further investigation or discovery; (4) the denials of factual contentions are warranted on the evidence or, if specifically so identified, are reasonably based on belief or a lack of information".

${ }^{13} 11.1$ Principios UNIDROIT (2004): "The parties and their lawyers must conduct themselves in good faith in dealing with the court and other parties".

${ }^{14}$ Art. 5 Código Procesal Civil Modelo para Iberoamérica (1988): "Buena fe y lealtad. Las partes, sus representantes o asistentes y, en general, todos los partícipes del proceso, ajustarán su conducta a la dignidad de la justicia, al respeto que se deben los litigantes y a la lealtad y buena fe". 
esfuerzo interpretativo, porque no son autoevidentes; de allí que sea importante destacar que esta empresa interpretativa ya se encuentra en marcha en la literatura procesal chilena.

En este trabajo se indagan tres formas conceptualmente diversas de dotar de contenido normativo a la buena fe procesal, con una especial atención en la justicia civil. Cada uno de estos enfoques responde a una imagen o idea previa de lo que debe ser la jurisdicción y el proceso judicial; la trilogía se compone de dos extremos y de una posición que puede ser vista como intermedia. La intención en lo que sigue es demostrar que ninguno de los polos -que denomino lectura fuerte y lectura mínima- reconstruye la mejor lectura en escenarios donde concurren intereses contrapuestos. En este tipo de situaciones cabe pensar en una tesis intermedia que sea capaz de equilibrar los intereses privados (de los litigantes y de los terceros) con los intereses públicos (que atiende la administración de justicia), a través de un conjunto de cargas y deberes procesales cuyos supuestos de aplicación estén claramente delineados por la legislación.

$\mathrm{El}$ artículo se desarrolla de la siguiente manera: una vez presentadas estas lecturas de la buena fe procesal, se aborda la concepción fuerte a la luz de tres problemas concretos (el acceso a las pruebas, la verdad de los hechos y la libertad argumentativa). En cada uno de ellos el texto explora las fortalezas y debilidades de la tesis fuerte de la buena fe; en segundo término, se expone la lectura mínima de la misma y el problema de la discrecionalidad de los tribunales en la aplicación de esta cláusula abierta. Aquí se defiende una idea que es relevante: la necesidad de contar con un marco regulatorio más o menos detallado de la buena fe procesal, junto con una práctica argumentativa (cánones de interpretación) que minimicen las probabilidades de error al momento de aplicar esta cláusula. Esta premisa sienta las bases para una tesis más que mínima de la buena fe procesal; una lectura bajo la cual no sólo sean repelidos los comportamientos dolosos en la litigación sino que, también, se reconozca en ella un espacio para los deberes. El artículo aborda, sólo a modo de ejemplos, dos de estos deberes procesales (colaborar con las pruebas y contestar fundadamente la demanda). Por último, se concluye con un análisis de las sanciones y de los principales desafíos que ellas le imponen a la legislación procesal: la tipicidad de los comportamientos, la (in)determinación de las sanciones y el procedimiento sobre la base del cual se imponen estas sanciones.

\section{TRES ASEDIOS A UNA ClÁUSULA ABIERTA}

Este análisis de la buena fe procesal podría remontarse sólo al año 2006, en vista de que el Código de Procedimiento Civil de 1903 nunca explicitó 
un compromiso con la buena fe del modo en que sí lo hizo el art. 8 del Anteproyecto de Código Procesal Civil:

"Buena fe procesal. Las partes, los terceros, y general, todos quienes deben acudir ante los tribunales deben ajustar su conducta a la dignidad de la justicia, al respeto de los derechos fundamentales de la persona humana y a la lealtad y buena fe procesal. (2) El tribunal, de oficio o a petición de parte, podrá adoptar durante el desarrollo del proceso todas las medidas que estime pertinentes para impedir o sancionar toda conducta u omisión que importe un fraude procesal, colusión o cualquiera otra conducta ilícita o dilatoria" 15 .

La fórmula de este "Anteproyecto" sería, tres años después, el art. 6 del Proyecto de Código Procesal Civil presentado al Congreso en el año 2009 (Boletín $\mathrm{N}^{\mathrm{O}}$ 6567-07), aunque con dos variantes que son significativas:

i) que el juez adopte medidas (no que "podrá adoptar") y

ii) que intervenga no solo para impedir, sino que también para prevenir y sancionar las infracciones a la buena fe procesal.

Este doble enfoque -imperativo y de prevención- fijaría, tres años más 264 tarde, la redacción del Proyecto de Código Procesal Civil del año 2012 (Boletín No 8197-07), cuyo art. 5 cambió dos expresiones muy genéricas ("dignidad de la justicia" y "respeto de los derechos fundamentales de la persona humana") por dos ideas que, si bien son de una amplitud considerable, tienen la 'ventaja' de que forman parte del bagaje conceptual de nuestros jueces:

"Buena fe procesal. Las partes, sus apoderados y todos quienes intervengan en el proceso deberán actuar de buena fe. (2) El tribunal, de oficio o a petición de parte, deberá prevenir, corregir y sancionar, según corresponda, toda acción u omisión que importe un fraude o abuso procesal, colusión, contravención de actos propios o cualquiera otra conducta ilícita, dilatoria o de cualquier otro modo contraria a la buena fe".

Se destaca este hecho, de que las categorías por las que apostó el Proyecto CPC 2012 tienen un cierto poder explicativo en nuestra literatura jurídica (abuso procesal, fraude, colusión y actos propios), aunque se trata, obviamente, de figuras cuyos contornos son aún muy amplios y que precisan de una labor interpretativa más o menos intensa. Para fomentar este debate es que el artículo propone una carta de navegación con tres

${ }^{15}$ Cfr. "Anteproyecto de Código Procesal Civil” (2006), p. 48. 
posibles rutas para que el intérprete le asigne un contenido normativo a la buena fe procesal:

1) Una lectura fuerte: impone a todos quienes intervienen en un juicio (litigantes, terceros y juez) un compromiso robusto con los intereses que atiende la administración de justicia. Esto justifica que la posición de parte (sea interesada o no interesada) esté sujeta a deberes de colaboración con respecto a los hechos -colaborar con las pruebas y 'decir la verdad'- y al debate jurídico -no contravenir sus actos-;

2) Una tesis mínima: se limita a marginar del proceso las actuaciones dolosas o abusivas, con lo cual garantiza la libre competencia entre los litigantes y

3) Una lectura más que mínima: no sólo purga los comportamientos dolosos sino que le impone a los intervinientes cargas y deberes delimitados por la legislación, con el fin de hacer probable el cumplimiento tanto de los intereses públicos como privados que convergen en el juicio.

Pero este artículo no sólo bosqueja un mapa hermenéutico sino que, también, se propone demostrar que la tesis más que mínima es la que mejor captura el papel que desempeña la buena fe en la justicia moderna. Para convencer de esto al lector será importante distinguir dos perspectivas en la buena fe procesal: entre las partes, ella es un desincentivo a las conductas dolosas; respecto de las partes y el proceso, en tanto, ella justifica la imposición de ciertos deberes a quienes participan en el juicio. Este binomio, por supuesto, supone no ser escépticos en cuanto a la división entre cargas y deberes como formas de canalizar las distintas actitudes que circulan en un proceso -tanto las posturas estratégicas como los gestos colaborativos-. Aquí se utiliza una distinción entre cargas y deberes procesales que atiende a sus consecuencias. ${ }^{16}$ Así, se hablará de carga si la conducta da lugar a la preclusión (i.e., a la imposibilidad de actuar en otro momento) y de un deber cuando su insatisfacción no sólo impida actuar más adelante sino que, también, traiga aparejado un efecto desfavorable para el sujeto que incumple (por ejemplo, tener por establecido un hecho en su contra si no colabora con la prueba), consecuencia que, incluso, podría implicar una sanción (multa o arresto).

El otro binomio relevante para este análisis lo entrega la distinción entre hecho y derecho, la cual provee de un hilo conductor para sondear las distintas manifestaciones de la buena fe procesal. Así, es en el campo de los hechos donde corresponde discutir si existe un deber de colabo-

\footnotetext{
${ }^{16}$ En esto se sigue a Eduardo Couture, con la libertad que autoriza su propio trabajo: Couture, (2002), pp. 171-175.
} 
ración con respecto al acceso a las pruebas, mientras que es en el ámbito del Derecho donde se ha de discutir sobre un deber de fundamentar la contestación de la demanda. Con todo, es preciso hacer una advertencia en torno a este segundo binomio: la distinción entre hecho y derecho es política, no ontológica; esto es, las cuestiones jurídicas no son sino una parte de una categoría más amplia -los asuntos de hecho- de modo tal que cuando se divide entre hecho y derecho a lo que se debe atender es a las consideraciones funcionales en cuya virtud algo es calificado de jurídico o de fáctico ${ }^{17}$.

Por último, me permito hacer dos consideraciones de carácter general. Dado que al postular (algo así como) una tercera vía interpretativa de la buena fe procesal existe la posibilidad de que los extremos refuercen sus posiciones y se multipliquen las objeciones por parte de ambos bandos, se piensa que éste no debiera ser el caso por lo siguiente: los trabajos escritos sobre la materia en Chile, así como la (aún escueta) jurisprudencia sobre el tema, convergen hoy en algo que es crucial: la buena fe justifica hablar de deberes (aunque ello se manifieste en clave mínima: el deber de no litigar con dolo). Este consenso podría dar inicio a una perspectiva diferente del estudio del proceso judicial -el enfoque de los derechos- en atención a que la contracara de esos deberes son los derechos ${ }^{18} ; \mathrm{y}$, en términos aún más amplios, ella podría servir para una aproximación diferente al Derecho Procesal como disciplina, una aproximación que no se agote en las normas legales, sino que también considere a las instituciones y a la metodología en su modo de analizar los problemas -el enfoque de la forma-. Esto último se ve en la relación entre la cultura de una comunidad y las formas de solucionar los conflictos como un intercambio recíproco ${ }^{19}$ : si la relación entre el proceso y la cultura no es instrumental en un sentido clásico -un medio para un fin-, sino que el medio (el juicio) anticipa en cierto modo el fin (la cultura de una comunidad que valora, por ejemplo, la paz social), el estudio, digamos, de la buena fe procesal tendría que expandirse desde las normas de un Código Procesal Civil hacia las distintas formas en que la comunidad da cuenta de esa relación (por ejemplo, si existen o no fondos públicos para que pueda cumplir con el deber de aportar pruebas la persona que no puede pagarlas, o si los mercados discriminan o no entre los abogados que honran la buena fe y aquellos profesionales que la defraudan). Pero éstas, como se dijo, son notas de índole muy general cuyo rendimiento no será abordado en este artículo.

${ }^{17}$ Allen y Pardo (2003), p. 1170.

${ }^{18}$ Alexander (1998), p. 19 y ss.

${ }^{19}$ Cfr. Chase (2005). passim; Taruffo (2000), p. 5 y ss. Desde un punto de vista técnico, véase STÜRNER (2003). p. 435 y ss. 


\section{Lectura fuerte}

La buena fe procesal es una cláusula que contribuye a que el juez dicte una sentencia justa. Esta idea apela a una cuestión que se ha vuelto común en el Derecho Procesal moderno: las partes deben ayudar al tribunal a conseguir, en el lenguaje del proceso civil inglés, "el objetivo primordial del juicio" ${ }^{20}$. Este fin primordial evoca el pensamiento de Jeremy Bentham en cuanto a que el único fin directo del juicio es un veredicto justo (otros fines no son sino secundarios) ${ }^{21}$, premisa que goza hoy de bastante popularidad en la literatura procesal: así, por ejemplo, en su German Civil Justice, Peter Murray y Rolf Stürner dicen que la función principal de los procesos judiciales es la de establecer y cumplir los derechos subjetivos y las obligaciones de las personas, mientras que la solución del conflicto en conformidad a derecho no es más que un fin vinculado a ese objetivo principal ${ }^{22}$. Esta fidelidad con el proyecto benthamiano, según el cual los jueces deben resolver los conflictos sobre la base de derecho como la mejor forma de implementar una vida en comunidad cimentada en derechos subjetivos y obligaciones, se ha redirigido, doscientos años después, hacia el debate sobre el espacio que la eficiencia (los costos y la duración del litigio) puede tener entre los fines del proceso. Pero sean cuales sean estos fines, lo que se hizo común, repito, es la intuición de que las partes deben colaborar para que se cumplan los objetivos que sirve la administración de justicia.

La lectura fuerte de la buena fe procesal ha capturado muy bien este punto. El puente entre la solución (justa y eficiente) del caso y los comportamientos que son admisibles en un litigio ha recibido de parte de ella el nombre de cooperación. Las reformas del último tercio del siglo Xx (véanse, por ejemplo, los procesos civiles de Alemania ${ }^{23}$ y Francia ${ }^{24}$ no han hecho

${ }^{20}$ Cabe notar que en su formato inicial de 1998 el énfasis en las Civil Procedural Rules se orientó a posibilitar (enable) esta meta: "These Rules are a new procedural code with the overriding objective of enabling the court to deal with cases justly and at proportionate cost" (Rule 1.1), mientras que tras su sexagésima actualización del 2013 (1 de abril) el acento estuvo en reforzar o consolidar (strengthen) esta posibilidad de satisfacer el objetivo fundamental de la administración de justicia: "The overriding objective of the rules is strengthened to enable to the courts to deal with cases justly and at proportionate cost" (Part 1).

${ }^{21}$ Bentham (1825), p. 5.

${ }^{22}$ Murray \& Stürner (2004), p. 4.

${ }^{23}$ Entre otras reglas, el deber de colaboración de los terceros ( $\$ 380$ Zivilprozessordnung). Véase Pérez Ragone (2005), pp. 402-404.

${ }^{24}$ Art. 11 Code de Procédure Civil (1978): “(1) Les parties sont tenues d'apporter leur concours aux mesures d'instruction sauf au juge à tirer toute conséquence d'une abstention ou d'un refus. (2) Si une partie détient un élément de preuve, le juge peut, à la requête de l'autre partie, lui enjoindre de le produire, au besoin à peine d'astreinte. Il peut, à la requête 
más que poner de manifiesto que "a justa composição do litígio" -en la fórmula portuguesa $-^{25}$ depende en buen grado de la cooperación de las partes tanto en los hechos como en el Derecho. En ambos casos la buena fe expresaría lo que Gian Antonio Micheli llamó, en L'onere della prova, un "principio de solidaridad social" 26.

De esta vinculación entre los fines del proceso y la conducta de las partes la concepción fuerte extrae al menos tres deberes para los litigantes:

a) aportar evidencias,

b) 'decir la verdad' y

c) no ir en contra de las propias actuaciones.

1.a) El acceso a las pruebas

Durante los debates de la reforma a la justicia civil chilena la idea de que los litigantes tuvieran que colaborar con el acceso a las pruebas acaparó gran parte de la atención; en especial, de parte de quienes pensaban que el art. 1698 del $C C$ ("incumbe probar las obligaciones o su extinción al que alega aquéllas o ésta") eximía de colaborar con la prueba de los hechos introducidos por el otro litigante. La discusión no podría más que concluir que la existencia de este deber de colaboración probatoria es pacífica en las legislaciones modernas, según se verá más adelante, aunque su extensión no lo es tanto. De allí la fórmula del Proyecto CPC 2012:

“Colaboración para la práctica de la medida probatoria. Los terceros y las partes tienen el deber de prestar la máxima colaboración para la efectiva y adecuada realización de las inspecciones, reconstrucciones y pericias. En caso de negativa injustificada de los terceros a prestar la colaboración, el tribunal adoptará las medidas conminatorias apropiadas remitiendo, si correspondiere, testimonio de lo actuado al Ministerio Público a los efectos pertinentes [...] Si quien debiera prestar colaboración fuera una de las partes y se negara injustificadamente a suministrarla, el tribunal le intimará a que la preste. Si a pesar de ello se persistiera en la resistencia, el tribunal dispondrá se deje sin efecto la diligencia, pudiéndose interpretar la negativa a colaborar en la prueba como una confirmación respecto del hecho que se quiere probar" (art. 337).

¿Se puede desprender de esta redacción una idea fuerte de la buena fe en el Proyecto CPC 2012? La respuesta dependerá, por supuesto, de los

de l'une des parties, demander ou ordonner, au besoin sous la même peine, la production de tous documents détenus par des tiers s'il n'existe pas d'empêchement légitime”.

${ }^{25}$ Art. 7 Código de Processo Civil. Véase Ferreira da Silva (2005). pp. 448-454.

${ }^{26}$ Micheli (1942), p. 156. 
alcances que se le atribuyan a la expresión "máxima colaboración”. Antes de interpretar este enunciando tendrían que recordarse los otros dos documentos que alimentaron el debate de la reforma. Por un lado, en el Anteproyecto CPC 2006 el tribunal debía interpretar una negativa a colaborar como la confirmación del hecho que se discutía en desmedro del litigante que no había cooperado, a menos que se demostrara algo distinto (art. 319). El Proyecto CPC 2009, en cambio, modificó ese imperativo (art. 299) por la tesis que conservaría luego el Proyecto CPC 2012: el juez puede tener por probado el hecho si una conducta no es colaborativa. La justificación de esta idea descansa en una máxima de la experiencia según la cual quien no colabora teme que sea conocido un hecho que no favorece sus intereses. Esta máxima debería hacerse visible (o transparente, como se dice hoy) a efectos de contrastarla con otras posibles explicaciones para la falta de cooperación (sin ir más lejos, la escasez de recursos de la persona llamada a colaborar). Lo que está en juego no es menor y se refiere a la autorización que da la ley a los tribunales para que ellos puedan crear conocimiento a partir de la ignorancia ${ }^{27}$.

Para zanjar este punto cabe hacer notar que el nexo entre la buena fe procesal y la valoración de la prueba se remonta al viejo $C P C$, a una disposición del juicio de mínima cuantía (art. 724) ${ }^{28}$ que la CS consideró "de orientación general" ${ }^{29}$. Este art. 724 autorizó, desde el año 1903, las inferencias procesales en la litigación civil patrimonial -atribuirle una consecuencia probatoria a la conducta de una parte $-^{30}$ de manera facultativa, no imperativa, con lo que se alejó de la tesis fuerte, según la cual el juez debe inferir de la falta de colaboración la prueba del hecho. Parece que, lo mismo que en 1903, la reforma chilena a la justicia civil se aleja de la tesis fuerte, por dos razones: primero, porque el Proyecto CPC 2012 (al igual que el Proyecto CPC 2009) faculta al juez para inferir que el hecho está probado (sólo en el Anteproyecto se contenía una fórmula imperativa) y, segundo, porque las inferencias procesales apelan a una razón exclusiva, pero no excluyente: el juez puede tener por acreditado el hecho en contra de los intereses de quien no colabora a menos que éste justifique su no cooperación. Dicho en otras palabras, el que se pueda reclamar una razón

${ }^{27}$ Se toma esta expresión de Porat \& Stein (2001), pp. 84-100.

${ }^{28}$ Art. 724 Código de Procedimiento Civil: "La prueba se apreciará en la forma ordinaria. Pero podrá el tribunal, en casos calificados, estimarla conforme a conciencia, y según la impresión que le haya merecido la conducta de las partes durante el juicio y la buena o mala fe con que hayan litigado en él”.

${ }^{29}$ Alarcón y otros con Empresa Constructora Emasil S.A. (2008) cons. $17^{\circ}$.

${ }^{30}$ Opto por el nombre inferencia procesal porque parece todavía más preciso que la denominación inferencia probatoria, elegida por Jordi Ferrer para dar cuenta de la expresión argomenti di prova, en su traducción de La prova dei fatti giuridice: TARUFFo (1992), p. 19. 
distinta al temor de que algo sea conocido porque perjudicaría a quien no colabora sugiere que el deber de "máxima colaboración" probatoria del Proyecto CPC 2012 no da cuenta de una idea fuerte de buena fe procesal.

En consecuencia, el desafío no pasa tanto por debatir si es posible o no un deber de colaboración en el acceso a las pruebas en los juicios civiles, sino en delimitar cuáles son sus alcances en la práctica, especialmente en lo que atañe a las inferencias procesales. En otros términos, no se trata de un problema existencial, sino operativo. Nuestra justicia civil no ha sido ajena a los deberes de colaboración probatoria; basta con recordar la solicitud de documentos como una medida cautelar previa a la demanda (art. 273 $\mathrm{N}^{\mathrm{o}} 3$ y 4 del $C P C$ ), algo que para un atento comparatista estadounidense no daba cuenta sino de "modestos derechos de exhibición" 31 , pero que entre nosotros fue entendido como un claro reconocimiento al principio de igualdad de los medios probatorios ${ }^{32}$. Una vez superada esta fase existencialista - ¿hay o no un deber de colaboración probatoria?- el siguiente paso es indagar los nexos entre la buena fe procesal, la recopilación de las evidencias y su valoración. Se trata, por lo demás, de un camino que ya fue señalado por los propios tribunales: así, la Corte de Apelaciones de Concepción, al resolver algunos casos de término del contrato de trabajo recogió una frase enigmática, "uno de los elementos de la sana crítica [...] es el principio de derecho del artículo 724 del Código de Procedimiento Civil" ${ }^{33}$, empleada a comienzos de la década de 1990 por la Corte de Apelaciones de Santiago, en Vega con Transportes Alfa Limitada ${ }^{34}$, el único caso que el Repertorio de Legislación y Jurisprudencia Chilenas en su cuarta edición del año 2010 vincula con esta regla ${ }^{35}$.

¿En qué sentido la buena fe procesal es un "principio de derecho" y "uno de los elementos de la sana crítica"? La respuesta a este enigma requiere de una mejor comprensión de lo que llamamos libertad de prueba y de la relación entre las cargas probatorias y los estándares de prueba, un aspecto donde la historia del art. $724 \mathrm{del} C P C$ tendrá algo que aportar.

\section{1.b) 'Decir la verdad'}

El segundo deber que emanaría de la buena fe procesal alude a la verdad del conflicto: según una idea fuerte de la misma, un proceso honesto exige que las afirmaciones sobre los hechos sean verdaderas. Para no redundar aquí sobre cuestiones que han sido latamente difundidas en la

\footnotetext{
${ }^{31}$ Cappalli (1992), p. 234.

${ }^{32}$ Barros Bourie (2006), $\mathrm{N}^{\text {Os }}$ 478-479, 679-680 (destacado en el original).

${ }^{33}$ Corte de Apelaciones de Concepción (2002), cons. 10.

${ }^{34}$ Vega con Transportes Alfa Limitada (1993), cons. $1^{\circ}$.

${ }^{35}$ Cfr. Repertorio de Legislación y Jurisprudencia Chilenas (2010), p. 316.
} 
literatura sólo se dirá el motivo por el cual se cree que la interpretación fuerte se equivoca al emplear la categoría de deber en este punto. Los procesos no exigen 'decir la verdad' en el siguiente sentido: la verdad es un concepto relacional, pues depende del contexto en que ella se indaga, por lo que siempre se encuentra supeditada a la calidad y cantidad de los datos que se logren recaudar. En consecuencia, lo que se afirma en un juicio puede no ser verdadero sin que por ello, necesariamente, sea falso. Esta zona intermedia es la que una tesis fuerte se resiste a aceptar: los procesos judiciales implican conceder un grado más o menos amplio de incertidumbre porque lo que allí se dice muchas veces no puede ser corroborado ni falseado, cuando se dicta la sentencia.

Pero el que no debamos 'decir la verdad' en un sentido fuerte (y que, por contrapartida, no exista un 'derecho a la verdad') no implica el extremo opuesto, de amparar un derecho a mentir. Varias son las conductas que resultan inadmisibles en consideración a la buena fe procesal y las tres tesis que se examinan en este artículo coinciden en ello: los intervinientes en un juicio no pueden engañar a la contraria o inducirla a error. Una vez que se cumple con este compromiso mínimo es preciso recordar que una litigación contenciosa es el típico escenario en que dos partes le cuentan a un tercero historias diversas, lo cual no implica que una mienta y que la otra diga la verdad ("porque cada uno ve las cosas desde su punto de vista y porque el mundo del derecho es el mundo de la duda") ${ }^{36}$.

En efecto, sin desconocer los casos de engaño o dolo, pareciera que lo más acuciante a la hora de narrar los hechos no es que las partes mientan o tergiversen groseramente lo sucedido, sino que las historias que le cuentan al tribunal sean -de buena fe- erróneas o incompletas, en un grado tal que se distorsione la prueba desviándola hacia hechos irrelevantes. Este problema (de la subconsideración o argumento del lote malo) podría llegar a ser un desafío, incluso, más punzante que el de la mentira, porque él cuestiona los alcances del principio de disposición de parte, en el sentido de que el monopolio sobre los hechos que tienen los litigantes podría llegar a obstaculizar la tarea del juez de fijar el predicado fáctico de la regla aplicable al caso ${ }^{37}$.

La salida que sugiere el Derecho Comparado a este respecto es imponerle al juez un deber de aclaración de los hechos. Así, en Alemania la Zivilprozessordnung del año 2002 ha conservado en su $\$ 138$ la idea de que "las partes deben hacer sus declaraciones sobre cuestiones de hecho en forma completa y adecuada a la verdad" 38 , e inmediatamente después

${ }^{36}$ Cipriani (2003), p. 284.

${ }^{37}$ Larroucau Torres (2012a), pp. 802-803.

${ }^{38}$ § 138 Zivilprozessordnung: "Deber de declaración sobre hechos: deber de decir la verdad: (1) Las partes deben hacer sus declaraciones sobre cuestiones de hecho en forma 
el $\S 139.1$ incluye el deber del juez de aclarar los hechos que le narran las partes $^{39}$. En un Derecho de corte liberal como el moderno ordenamiento alemán, una regla como el $\S 138$ no puede sino entenderse a la luz de una lectura no escéptica acerca del establecimiento de hechos verdaderos. La búsqueda de la verdad no es un señuelo ("specchietto per le allodole") ${ }^{40}$ como sostienen algunos escépticos, sino que un ideal regulador de la litigación, puesto que al aproximarnos a la verdad minimizamos las probabilidades de errores en el fallo y, desde el ángulo inverso, maximizamos las probabilidades de que el juez conozca el caso en sus propios términos. El $\S 138$ del $Z P O$ vendría a ser el paradigma normativo de este ideal (en la medida en que se refiere a las partes interesadas en el conflicto), recogido en Chile por el Proyecto CPC 2012 (art. 310) para las partes no interesadas (testigos), respecto de las cuales los dos documentos anteriores habían hablado -incorrectamente- de una "obligación" de decir la verdad (art. 295 del Anteproyecto CPC 2006 y art. 276 del Proyecto CPC 2009).

Sin perjuicio de que este asunto amerita de una discusión mucho más profunda que lo que aquí se pueda decir, se estima que las partes (interesadas o no) cumplen con la buena fe procesal cuando expresan sus discursos como si fueran verdaderos (lo que ayuda de paso a la eficiencia judicial, puesto que permite prescindir de filtros adicionales que aseguren la fidelidad de los datos $)^{41}$. Las condiciones procesales para que una narración sea verosimil (o cuente como si fuera verdadera) no pueden discutirse en este lugar ${ }^{42}$, pero una vez que ellas concurren me inclino a pensar que la integridad de los relatos -que los hechos encajen con las palabras- no tendría que expresarse en mayores compromisos normativos.

completa y adecuada a la verdad. (2) Cada parte debe declarar sobre las alegaciones de hecho de su contraparte. (3) Los hechos que no sean discutidos en forma expresa deben considerarse como admitidos, cuando no pueda inferirse la intención de discutirlos de las declaraciones que efectúen las partes. (4) Una declaración fundada en el desconocimiento es solamente admisible en tanto verse sobre hechos que no dependan de los actos propios de la parte ni de un objeto que se encuentre bajo su control".

${ }_{39}$ \$ 139.1 Zivilprozessordnung: "Impulso procesal material: (1) El tribunal tiene que esclarecer la relación de hecho y la litis y, en tanto ello sea necesario, con las partes en las cuestiones de hecho y de derecho aclarándolas y realizando preguntas. Él tiene que lograr que las partes en forma completa y oportuna declaren sobre los hechos relevantes, en especial aclaraciones insuficientes que hacen a los hechos invocados a los efectos de completarlos para describir los medios de prueba y para interponer las peticiones que se adecuen a la causa".

${ }^{40}$ Monteleone, Girolamo (2009), p. 4.

${ }^{41}$ Coloma Correa (2006), pp. 37-41.

${ }^{42}$ Para un análisis más detenido: TARUfFo (1992) capítulos I y III. 
1.c) Los actos propios (o sobre la libertad argumentativa y el derecho de defensa)

Los abogados saben que no pueden decir cualquier cosa en un juicio, ni cuando aluden a los hechos, ni cuando discuten sobre el derecho. Para una lectura fuerte, en particular, 'decir la verdad' y colaborar con la prueba no agotan el sentido de la buena fe procesal; es necesario, además, contar con un deber que se haga cargo del debate jurídico, un deber que estipule que las partes no pueden contradecir o modificar sus afirmaciones previas. Pero, ¿cómo se podría restringir la libertad argumentativa de los abogados mediante la buena fe? Nadie dudaría de que la racionalidad de las partes en un juicio contencioso tienda a expresarse en términos horizontales, como una serie de acciones que van encaminadas hacia metas específicas ${ }^{43}$ y que esas conductas merecen un reconocimiento procesal porque expresan la autonomía de cada uno de los sujetos que participan en la discusión. Toda restricción a esta libertad, por ende, ha de justificarse con algún motivo plausible.

En el apartado anterior se sostuvo que las estrategias de las partes acerca de los hechos no deberían neutralizarse mediante un compromiso radical con la verdad. ¿Qué ocurre, entonces, con las maniobras que apuntan a la ley aplicable o, mucho más difícil todavía, a la forma en que esa ley debe ser interpretada por el juez? Desde un punto de vista amplio, el asunto se vincula con la independencia de los tribunales respecto de la calificación jurídica que las partes hacen en sus escritos de demanda y contestación: durante el siglo xx nuestros jueces civiles acordaron -vía iura novit curia- que no estaban atados a las interpretaciones de los litigantes $^{44}$. Desde el ángulo de la buena fe procesal, en cambio, el asunto sigue abierto: ¿cuál es el margen de acción que tienen los abogados cuando discuten sobre el Derecho aplicable? La tesis fuerte ha querido colonizar esta libertad argumentativa mediante una aplicación extensiva de la vieja doctrina que prohíbe ir en contra de los propios actos. Así, para la interpretación fuerte es un (tercer) deber de los litigantes no contradecir o alterar el fundamento jurídico planteado al inicio del juicio (o, incluso, antes), ya sea de forma explícita o tácita.

Tal como en el primer caso respecto al acceso a las pruebas, es la extensión que la tesis fuerte le atribuye a este deber la que resulta excesiva. Imponerle a las partes de forma tan contundente un deber de coherencia en el debate podría transformar a la buena fe en un "criterio de moralización" de los procesos ${ }^{45}$. Nótese que la exigencia de que los jueces conozcan el Derecho vigente se justifica, en parte, como una forma de garantizar la liber-

\footnotetext{
${ }^{43}$ Por todos Calvo Soler (2003), p. 21.

${ }^{44}$ Hunter Ampuero (2010), p. 197 y ss.

${ }^{45}$ La expresión es de Romero Seguel (2003), pp. 169-170.
} 
tad en la argumentación jurídica, con lo cual se honra el derecho de defensa anotado en la Constitución (art. $19 \mathrm{~N}^{\mathrm{o}} 3$ inciso $1^{\circ}$ ), tal como lo ha entendido nuestro Tribunal Constitucional ${ }^{46}$. La doctrina de los actos propios, por tanto, si es que algún papel tiene que desempeñar en la litigación, es uno de contenido mínimo: evitar el abuso y las dilaciones, así como impedir que las partes presenten argumentos que son de una incongruencia intolerable.

Dado que el Proyecto CPC 2012 incluyó a los actos propios entre las modalidades típicas de infracción a la buena fe procesal se vuelve necesario explorar los desafíos procesales de esta figura, los cuales esta tensión entre libertad argumentativa y derecho de defensa pretende resumir. Pero si sólo se acudiese al lenguaje constitucional para efectuar este análisis probablemente la cuestión se congelaría en la pugna entre el derecho (fundamental) a una defensa en el juicio y el derecho (fundamental) a una tutela judicial efectiva, sobre la base de un debido proceso ${ }^{47}$. En términos procesales, en cambio -y se entiende que esta cuestión se debería escribir con una gramática procesal- el asunto pasa por disolver dudas del siguiente tenor: ¿ cómo introducir en un juicio argumentos jurídicos incompatibles entre sí pero útiles a los intereses del cliente?, ¿̇se puede cambiar un argumento jurídico cuando se recurre el fallo ante una Corte?, ¿qué limitaciones se derivan de los juicios que ya se han litigado?, ¿debe tratarse de juicios seguidos en contra de la misma parte o también cuentan los que se litigan en contra de terceros? Me parece que buena parte de estas preguntas ya estaban implícitas en la autorización del art. 17 inciso $2^{\circ} \operatorname{del} C P C^{48}$ a raíz de las pretensiones incompatibles que pueden enhebrar los abogados, pero no cabe ahora dar cuenta de ellas ${ }^{49}$.

Tampoco es éste el lugar para analizar la forma en que nuestros jueces civiles han aplicado la tesis de los actos propios ${ }^{50}$. Baste con señalar que en la reciente jurisprudencia chilena se han cultivado (al menos) dos variantes de los actos propios: una aplicación extensiva (de la cual un ejemplo notable es Villanueva con Sanhueza) $)^{51}$ y una aplicación restringida, la cual reconduce los actos propios hacia las conductas abusivas o frívolas (como sería invocar reglas derogadas o entorpecer el trabajo judicial, al modo

${ }^{46}$ Bordalí Salamanca (2011), pp. 328-330.

${ }^{47}$ Para una posición escéptica: Hunter Ampuero (2008), pp. 158-164. Para un argumento favorable a la buena fe desde una perspectiva constitucional: Picó I JunOY (2006), p. 331 y ss.

${ }^{48}$ Art. 17 Código de Procedimiento Civil: "En un mismo juicio podrán entablarse dos o más acciones con tal que no sean incompatibles. (2) Sin embargo, podrán proponerse en una misma demanda dos o más acciones incompatibles para que sean resueltas una como subsidiaria de otra".

${ }^{49} \mathrm{Al}$ respecto: Larroucau Torres (2012c), p. 461 y ss.

${ }^{50}$ Véanse los fallos recopilados en ConTARdo González (2010), p. 81 y ss.

${ }^{51}$ Villanueva con Sanhueza (2001), cons. $3^{\circ}$. 
en que ocurrió en Inmobiliaria Alameda de Antofagasta con Vergara) ${ }^{52}$. La opinión es que este segundo sentido es el correcto ${ }^{53}$.

Para recapitular lo dicho hasta ahora, la lectura fuerte de la buena fe procesal identifica tres deberes que regulan la conducta de las partes:

a) un deber de máxima colaboración en el acceso a las pruebas,

b) un deber de 'decir la verdad' en sus afirmaciones acerca de los hechos y

c) un deber de no alterar o contradecir ninguna posición jurídica previa en la que haya podido confiar la contraparte.

Por las razones señaladas, se estima que ninguno de estos deberes tiene la extensión que una tesis fuerte pretende, no obstante lo cual se comparte su punto de partida: son deberes procesales y no cargas, porque su incumplimiento no se agota en la preclusión. Esto marca una gran diferencia con la tesis mínima de la buena fe (que niega los deberes, salvo uno), pero sintoniza con la tesis más que mínima (que defiende estos deberes, aunque con otros márgenes).

\section{Lectura mínima}

La buena fe procesal es un freno a la litigación dolosa. Para todos quienes intervienen en un juicio existe la barrera de actuar sin malicia y sin abusar de las herramientas del proceso (nótese que a pesar de sus diferencias conceptuales la tesis mínima habla de abuso, mala fe, ánimo dilatorio, entorpecimiento y fraude como ideas equivalentes). Desde este punto de vista la función del proceso es la de solucionar los conflictos, en el preciso sentido que Mirjan Damaška le dio a la expresión: un lugar donde los hechos y el Derecho no son controlados por el tribunal porque éste es simplemente una 'tabla rasa hábil' autorizada por la ley para zanjar los asuntos de los litigantes ${ }^{54}$. Pero, incluso, en un proceso como 'cosa de partes' no puede tener cabida el fraude, que todo lo corrompe.

\section{2.a) Fraus omnia corrumpit}

El programa de la tesis mínima es doble: primero, ella entiende que el compromiso de las partes con la administración de justicia es exiguo -no comportarse de forma dolosa- $y$, segundo, que dirimir lo que cuenta como malicia (dolo, fraude o entorpecimiento) no depende de las preferencias

${ }^{52}$ Inmobiliaria Alameda de Antofagasta con Vergara (2007), cons. $10^{\circ}$.

${ }^{53}$ Para un enfoque reticente a aplicar los actos propios en el ámbito procesal, véase: CARretTa Muñoz (2013). Se le agradece al autor el haber facilitado una copia de su trabajo.

${ }^{54}$ DAMAŠKa (1986), pp. 169-252. 
de cada juez. Esta segunda pieza es generalizable a las otras dos lecturas de la buena fe procesal, donde también es un desafío darle contenido al "fraude, la colusión, el abuso del derecho y las actuaciones dilatorias", para decirlo con la regla laboral chilena (art. 430 inciso $1^{\circ}$ del Código del Trabajo) o, en términos del Proyecto CPC 2012, al

"fraude o abuso procesal, colusión, contravención de actos propios o cualquiera otra conducta ilícita, dilatoria o de cualquier otro modo contraria a la buena fe" ${ }^{55}$,

sin caer en una discrecionalidad fuerte de los jueces.

Dado que no se comparte el primer punto de esta tesis de la buena fe (un tenue compromiso de las partes con la litigación, fruto de una imagen del proceso que no lo promueve como una forma de establecer y cumplir derechos y obligaciones), la concentración se pondrá en la segunda parte de su agenda: el riesgo de la discrecionalidad de los jueces. Procediendo, de esta forma, no porque se ignore el primer punto, sino porque este segundo problema (transversal a las distintas lecturas) es el que sienta las bases para demostrar que este compromiso mínimo con los fines del proceso - una 'cosa de partes' - no reconoce de la mejor forma el sentido de contar con un servicio de justicia en una comunidad que se ciñe a reglas.

En este orden de ideas es preciso descartar la vía con que la tesis mínima ha querido bajarle el perfil al tema de la discrecionalidad. Para la tesis mínima la discrecionalidad judicial no es tan preocupante porque la estructura de la buena fe es negativa: implica que no se puede proceder de mala fe en un juicio -el énfasis recae en no actuar- de modo que la litigación no concibe más que abstenciones o prohibiciones -no acciones o deberes de actuación- ${ }^{56}$. Este diseño (supuestamente) reduciría el riesgo de discrecionalidad lo suficiente como para que no fuese un peligro, porque bastaría con que se actúe por sobre los márgenes permitidos para que el juez constate una infracción a la buena fe. La salida es bastante ingenua, sin lugar a dudas, porque, incluso, para una lectura mínima la cuestión de qué cuenta como una infracción a buena fe procesal, entendida ésta como fraude (abuso o entorpecimiento) no es algo autoevidente. La penumbra que ronda a esta

${ }^{55}$ La misma tendencia a las fórmulas genéricas se puede apreciar, por ejemplo, en el Proyecto de Código Modelo de Procesos Administrativos -Judicial y Extrajudicial-para Iberoamérica del año 2012, art. 48: “(Buena fe y lealtad procesal). Las partes, sus representantes o asistentes y, en general, todos los participantes del proceso, ajustarán su conducta a la dignidad de la justicia, al respeto que deben los litigantes y a la lealtad y a la buena fe. $\S$ $1^{\circ} \mathrm{El}$ órgano jurisdiccional deberá impedir el fraude procesal, la colusión y cualquier otra conducta ilícita o dilatoria. $\S 2^{\circ}$ Serán previstas sanciones para el incumplimiento de los deberes de lealtad y buena fe o de cualquier otra conducta ilícita o dilatoria".

${ }^{56}$ Montero Aroca (2006), pp. 351-353. 
tesis no impide que el asunto -la pregunta por los márgenes permitidossea visto, en último término, como una cuestión que "depende del juez"

El punto aquí no es desconocer que la buena fe sí implica una apuesta por la destreza de los jueces, más aún si los jueces en Chile ya han demostrado que pueden justificar su infracción con buenas razones y no sobre la base de inclinaciones personale ${ }^{58}$. El asunto aquí es otro, diverso de la confianza que hemos depositado en los tribunales y se refiere a la función que desempeña la buena fe dentro de la administración de justicia. Bajo su mejor lectura, como se espera que se vea luego, implica una forma de distribuir el riesgo de censurar una conducta que debió haber sido permitida en el juicio, así como de fomentar ciertos comportamientos durante la litigación, en desmedro de otros, que sin la vigencia de esta cláusula probablemente no habrían tenido lugar. Para que esta propuesta sea viable en el contexto de una comunidad donde las decisiones de los jueces no se toman sobre la base de sus preferencias, se requiere de una pauta legal y de recursos interpretativos que le permitan a cada juez decidir qué conducta es impropia del litigio, sea que se trabaje al amparo de una cláusula abierta (como es el caso de la justicia del trabajo chilena) o, más aún, a la intemperie normativa (como ocurre con nuestra justicia de familia). Recuérdese que la buena fe es una cláusula ubicua en tanto rige para toda clase de juicios, en sus diversas dimensiones (cautelar, declarativa o ejecutiva). Su reconocimiento en el Código Procesal Civil, cuya aplicación supletoria continúa la senda del $C P C$, despeja cualquier duda al respecto.

\section{2.b) Los pasos perdidos (un marco regulatorio amplio}

y los cánones de interpretación)

El desembarco legal de la buena fe procesal implica dar dos pasos: primero, pensar en un marco normativo de referencia más o menos explícito y, segundo, debatir los cánones interpretativos que hacen operativo ese marco en la práctica. El argumento de fondo aquí es que resulta necesario superar el enfoque a partir de cual se ha explorado -un principio que inspira a la justicia-y optar por un análisis de corte normativo, donde contribuye a minimizar los riesgos de error que entraña la administración de justicia, por la vía de alentar algunas conductas y repeler otras. Desde este punto de vista, la buena fe procesal es una cláusula que justifica deberes y derechos, de modo tal que las políticas que le subyacen en cada uno de esos derechos y deberes han de ser definidas de antemano ${ }^{59}$.

${ }^{57}$ Domínguez Águila (1991), p. 34.

${ }^{58}$ Opazo con Brown y otro (2007), cons. $16^{\circ}$. Para un completo análisis de este fallo: WALKer Silva (2011), p. 211 y ss.

${ }^{59}$ Véase Bone (2008), p. 319 y ss. 
i) En un primer paso, entonces, la buena fe se traduce en una carta de navegación que informa sobre lo que tiene cabida en un juicio. Con esto no se quiere decir que la ley deba domesticar en detalle los supuestos de hecho de todo lo que puede ocurrir en un litigio; ello no es posible, ni deseable (un intento poco feliz en este sentido lo ofrece nuestra legislación del trabajo:

"se entenderá por actuaciones dilatorias todas aquellas que con el sólo objeto de demorar la prosecución del juicio sean intentadas por algunas de las partes",

art. 430 inciso final del Código del Trabajo). Las formas de expresión en un litigio son múltiples y en cierto modo imprevisibles, de modo que lo que un marco de referencia hace es proveernos de la información básica acerca de los límites que se van a tolerar. En el Código de Processo Civil de Brasil, particularmente en sus presunciones de mala fe e indemnizaciones del "daño procesal” (art. 17), encuentro un referente de la idea que trato de comunicar:

"Reputa-se litigante de má-fé aquele que:

I. Deduzir pretensão ou defesa contra texto expresso de lei ou fato incontroverso;

II. Alterar a verdade dos fatos;

III. Usar do processo para conseguir objetivo ilegal;

IV. Opuser resistência injustificada ao andamento do processo;

V. Proceder de modo temerário em qualquer incidente ou ato do processo;

Vl. Provocar incidentes manifestamente infundados;

VII. Interpuser recurso com intuito manifestamente protelatório".

La Comissão de Juristas Responsável pela Elaboração de Anteprojeto de Código de Processo Civil conservó el año 2010 esta misma lista (art. 69), que tiene un correlato en otros países del sur de América (véanse la legislación procesal civil peruana ${ }^{60}$ y colombiana $)^{61}$. Como se puede ver, se trata de

${ }^{60}$ Art. 112 Código Procesal Civil: "Temeridad o mala fe. Se considera que ha existido temeridad o mala fe en los siguientes casos: 1 . Cuando sea manifiesta la carencia de fundamento jurídico de la demanda, contestación o medio impugnatorio; 2. Cuando a sabiendas se aleguen hechos contrarios a la realidad; 3. Cuando se sustrae, mutile o inutilice alguna parte del expediente; 4 . Cuando se utilice el proceso o acto procesal para fines claramente ilegales o con propósitos dolosos o fraudulentos; 5 . Cuando se obstruya la actuación de medios probatorios; 6. Cuando por cualquier medio se entorpezca reiteradamente el desarrollo normal del proceso; y 7. Cuando por razones injustificadas las partes no asisten a la audiencia generando dilación".

${ }^{61}$ Art. 79 Código General del Proceso: "Temeridad o mala fe. Se presume que ha existido temeridad o mala fe en los siguientes casos: 1 . Cuando sea manifiesta la carencia de 
catálogos amplios, tanto porque no logran vadear los entresijos de nuevas zonas grises (el Código de Processo Civil brasileño habla de "objetivo ilegal", "temerario", "manifiestamente infundado", "alterar la verdad de los hechos" o "resistencia injustificada"), como porque sólo se interesan por aquellas actitudes o conductas más relevantes en un juicio. Lo que se considera útil en estos casos es que la cláusula no se agote en el adjetivo (abusivo, fraudulento, malicioso, dilatorio), sino que describa, aunque sea de un modo escueto, un conjunto de comportamientos que tienen lugar en las zonas de la litigación que son más sensibles a los fines del proceso (la prueba de los hechos, los incidentes, las defensas, los recursos, las audiencias). Una vez hecho esto y dado que en último término es el juez quien decide, para minimizar los márgenes de discrecionalidad en su trabajo es que se requiere un segundo paso: dilucidar los cánones que informan acerca del universo de sentidos que pueden endosarse a cada una de las piezas legales ${ }^{62}$.

ii) En términos de práctica argumentativa, la buena fe procesal no presenta diferencias relevantes con la empresa de la buena fe en el Derecho Civil Patrimonial: en ambos casos se trata de establecer un modelo de conducta. En el Derecho Civil de las Obligaciones, al ampliar o restringir los alcances de un contrato (art. $1546 \mathrm{del} C C$ ) y en las reglas del dominio y la posesión (art. $706 \mathrm{del} C C$ ), lo que este principio propone es un modelo sobre la base del cual contrastar una determinada conducta ${ }^{63}$. En el caso de la buena fe procesal, en particular, se trata de que los jueces mensuren el desempeño de las partes (tanto las interesadas como las no interesadas), así como sus propias decisiones, mediante un modelo de conducta que haga probable alcanzar los fines del proceso.

A la hora de refinar los cánones interpretativos que dotan de contenido a este concepto, la contribución de los propios jueces resulta de enorme valor; así lo ha demostrado Joan Picó i Junoy ${ }^{64}$. No obstante, este aporte no puede oscurecer la contribución que se espera que haga la propia literatura procesal, un aspecto donde, salvo notables excepciones, nuestra academia aún se encuentra en deuda. En Chile, donde la buena fe procesal

fundamento legal de la demanda, excepción, recurso, oposición o incidente, o a sabiendas se aleguen hechos contrarios a la realidad. 2. Cuando se aduzcan calidades inexistentes. 3. Cuando se utilice el proceso, incidente o recurso para fines claramente ilegales o con propósitos dolosos o fraudulentos. 4. Cuando se obstruya, por acción u omisión, la práctica de pruebas. 5. Cuando por cualquier otro medio se entorpezca el desarrollo normal y expedito del proceso. 6. Cuando se hagan transcripciones o citas deliberadamente inexactas".

${ }^{62}$ Atria Lemaitre (2002), pp. 351-352, 355-359.

${ }^{63}$ Guzmán Brito (2002), p. 11 y ss.

${ }^{64}$ Picó i Junoy (2013), pp. 387-438. 
suele entenderse en un sentido mínimo - un freno a la litigación dolosa- ${ }^{65}$, es poco lo que se ha avanzado en términos de saber cuándo se puede hablar de mala fe (abuso, fraude o dilación) ${ }^{66}$. Para cambiar esta situación es preciso, por un lado, acudir a la experiencia de otras disciplinas que se han enfrentado a las mismas categorías: así, por ejemplo, al derecho Privado (abuso del derecho), ${ }^{67}$ que distingue entre un abuso en el proceso $\mathrm{y}$ un abuso del proceso, a la litigación penal (estafa procesal) ${ }^{68} \mathrm{y}$ a la libre competencia (colusión), que matiza entre las conductas leales y desleales entre quienes participan en un mercado. Pero, junto con ello, también es necesario volver sobre la distinción que fue enunciada al comienzo, entre cargas y deberes. Las primeras, como se dijo, acuden a la preclusión al agotar la posibilidad de hacer más adelante lo que pudo hacerse en este momento; los segundos, en tanto, entrañan una consecuencia que es adicional a la preclusión y desfavorable para quien los incumple. La que denomino una tesis más que mínima de la buena fe procesal interpreta esta cláusula como un conjunto de cargas y deberes que pretende capturar los modelos de comportamientos esperados y con ello minimizar los riesgos de error que entraña censurar o fomentar conductas durante un juicio.

En la literatura procesal clásica, las cargas y los deberes siempre han sido dos categorías complementarias, pero en un sentido acotado: mientras las partes actúan movidas por cargas, el juez lo hace por deberes ${ }^{69}$. En la interpretación que se postula, en cambio, los deberes también ingresan a la esfera de los litigantes (i.e., a la zona de los hábitos egoístas), lo que bifurca el análisis de la buena fe procesal: entre los sujetos procesales filtra el dolo, pero en relación con la administración de justicia la cláusula se traduce en cargas y deberes cuya proporción dependerá de los intereses protegidos en cada caso.

\section{Lectura más que mínima}

La buena fe procesal hace probable que los intervinientes colaboren con las finalidades que sirve la administración de justicia. Esto es así porque ella lee al proceso como una forma de resolver los conflictos a través de normas y, con ello, como una forma de establecer una vida en comunidad

${ }^{65}$ En esta orientación se inscriben los artículos de Bordalí y MARín (2005), pp. 254-

256; Gorigoitía АвоTt (2008), pp. 144-149; Hunter (2008), pp. 164-178; Larroucau García (2010), p. 79.

${ }^{66}$ Una importante excepción en cuanto a las hipótesis de abuso es el trabajo de Pía Tavolari: TAVOlari GoYcoOleA, pp. 90-98.

${ }^{67}$ Barros (2006), capítulo IX.

${ }^{68} \mathrm{Al}$ respecto, véase: Hernández Basualto (2010), p. 201 y ss.

${ }^{69}$ Por todos: Sentís Melendo (1964), p. 9 y ss. 
basada en derechos y obligaciones. Se trata de una concepción atenta al hecho de que en un juicio concurren intereses privados y públicos que es preciso calibrar; algo que las dos lecturas anteriores, según se ha visto, no hacen. La postura fuerte se inclina demasiado por el interés público -una sentencia justa-, lo que impide que los ciudadanos puedan predecir con algo de estabilidad el desarrollo del proceso; la lectura mínima, en tanto, promueve con tesón los intereses privados y difumina la dimensión pública del juicio, casi por completo. En la lectura más que mínima, en cambio, se promueve un equilibrio entre ambos intereses, con lo cual se reconstruye de una manera más fidedigna el sentido de que dos partes acudan ante un juez para que éste zanje sus diferencias.

Las dos primeras lecturas reducen a la buena fe-como dice Joan Picó i Junoy- a dos caras de una misma moneda:

"en todo proceso es exigible que cualquier interviniente actúe con buena fe procesal o, si se quiere en otras palabras, se le prohíba actuar con mala fe procesal" 70 .

Dos caras que, se insiste, no son capaces de capturar los matices del proceso judicial. Parece que Georg Lichtenberg tenía razón en eso de que "no todo lo que se dice seriamente es, por ese solo motivo, razonable", porque, aunque suena bien decir que al amparo de la buena fe procesal no se podría esperar conductas, en el juicio, que fuera de él las personas no tendrían que cumplir, ello sólo es aceptable si entendemos al juicio como una 'cosa de partes'. Si el único propósito del juicio es la solución del conflicto, entonces la buena fe procesal no podría ser más exigente en el campo de las acciones estratégicas (como la prueba de los hechos) que lo que es fuera del proceso en el caso de algunas figuras colaborativas (como el contrato).

Para ejemplificar cómo la lectura más que mínima rompe con esta imagen del proceso es útil, en cuanto a los hechos, volver al caso de la colaboración probatoria y, en cuando al debate jurídico, acudir al caso de la contestación de la demanda. Como este artículo ya se ha extendido bastante, no corresponde esbozar aquí un catálogo de cargas y deberes para una clase de juicio en particular, sin perjuicio de lo cual se estima que estos dos ejemplos ilustran el modo en que la buena fe promueve una idea del proceso que supera a la del juicio como "cosa de partes". Quien así lo estime puede omitir estas páginas relativas a la justificación de ciertos deberes procesales e ir directamente a la última parte del texto donde se analizan las sanciones por conductas que infringen la buena fe procesal.

${ }^{70}$ Picó I Junoy (2013), p. 69. 
1.a) De nuevo sobre el acceso a las pruebas

La idea de que el juicio es la última forma de resolver un conflicto sirve de apoyo a la colaboración entre las partes, por dos razones: primero, porque si ellas cooperan antes de ir a juicio, incrementaran las probabilidades de solucionarlo de común acuerdo sin necesidad de litigar y, segundo, porque en el caso de tener que ir a juicio aumentarán también las probabilidades de obtener una sentencia justa y eficiente. Esta intuición fue fundamental en la reforma inglesa de 1998. Para dar un solo ejemplo, cuando alguien rechaza sin motivos plausibles una propuesta de salida alternativa al juicio, se expone a perder las costas, ya que su monto va a depender (entre otros factores) de "los esfuerzos hechos, antes y durante el proceso en orden a tratar de resolver la disputa"71. La jurisprudencia inglesa ha sido clara al respecto: el litigante vencedor podría perder su derecho a las costas si no coopera con la tarea del juez ${ }^{72}$. Es este mismo horizonte de cooperación con el juez el que justifica los deberes de las partes en cuanto a la recopilación de las pruebas.

Para informar de los alcances de esta cooperación en el acceso a las pruebas es preciso establecer reglas, tanto para los terceros no interesados como para quienes litigan. De allí que existan en el Derecho Comparado, por ejemplo, normas que formalizan lo que los testigos depondrán durante 282 la audiencia (declaraciones juradas o affidavits), reglas que apuntan a la eficiencia -impedir que el interrogatorio consuma el valioso tiempo de la audiencia- y a la lealtad del testigo -en cuanto a que sus afirmaciones serán veraces y exactas-. En este sentido se expresan, entre otras, las legislaciones de Francia ${ }^{73}$, Inglaterra ${ }^{74}$ y Alemania ${ }^{75}$.

${ }^{71}$ Rule 44.4 Civil Procedure Rules: "(1) The court is to have regard to all the circumstances in deciding whether costs were- (3) The court will also have regard to- (a) the conduct of all the parties, including in particular- (ii) the efforts made, if any, before and during the proceedings in order to try to resolve the dispute".

${ }_{72}$ Dunnett v. Railtrack plc (2002) 2 ALL ER 850, citado en CABrillo \& FitzPatrick (2008), p. 218 n. 60.

${ }^{73}$ Art. 200.1 Code de Procédure Civil: "Les attestations sont produites par les parties ou à la demande du juge"; art. 202.1: "L'attestation contient la relation des faits auxquels son auteur a assisté ou qu'il a personnellement constatés"; art. 203: "Le juge peut toujours procéder par voie d'enquête à l'audition de l'auteur d'une attestation”.

${ }^{74}$ Rule 32.4 Civil Procedure Rules: "(1) A witness statement is a written statement signed by a person which contains the evidence which that person would be allowed to give orally. (2) The court will order a party to serve on the other parties any witness statement of the oral evidence which the party serving the statement intends to rely on in relation to any issues of fact to be decided at the trial", Rule 22.4 (1): "The court may order a person who has failed to verify a document in accordance with rule 22.1 to verify the document".

${ }^{75}$ § 377.3 Zivilprozessordnung: "El tribunal puede ordenar que las preguntas sean respondidas en forma escrita cuando, en virtud de su contenido y de la persona del 
En cuanto al deber de colaboración de las partes interesadas es preciso distinguir dos momentos: antes y durante el proceso judicial. La litigación inglesa es particularmente sensible a la cooperación antes del juicio; así, por ejemplo, en Inglaterra existen varios protocolos que se aplican a las conductas anteriores a la demanda (pre-action-protocols), además de normas específicas para ciertos conflictos, como los daños (personal injury claims) o la negligencia médica (disease and illness claims). A estos marcos normativos es preciso añadir el disclosure ${ }^{76}$, cuyo objetivo es triple: preparar el juicio de manera imparcial, minimizar los costos e incentivar una salida alternativa $^{77}$. La experiencia estadounidense, en tanto, contiene disposiciones que van en la misma línea de hacer probable la cooperación probatoria desde la fase previa al juicio (discovery) $)^{78}$; así se explica, por ejemplo, la regla de que en el juicio sólo se admitirán aquellos datos que han sido revelados de forma oportuna (para Mirjan Damaška esto representa "una efectiva sanción, que salva la integridad de la competencia en el establecimiento de los hechos" ${ }^{79}$. De allí que en Pavlinko v. Yale-New Haven Hospital se fallara que una víctima no puede pedirle al tribunal el expediente clínico del hospital si durante el discovery ella misma se negó a explicar cómo es que perdió su copia del registro ${ }^{80}$. Durante el juicio, en tanto, la cooperación también se expresa a través de reglas claras ${ }^{81}$ : así, en Inglaterra quien tiene un documento - una categoría que la propia ley define $-{ }^{82}$ debe hacer una "búsqueda razonable" del mismo -lo que se

testigo, ello aparezca como suficiente. El testigo debe ser advertido de que puede ser citado para declarar. El tribunal ordena la citación del testigo cuando ello se considere imprescindible para la aclaración subsiguientes de preguntas con relación a la prueba", § 378.1: "En tanto aparezca como adecuado para facilitar la declaración, el testigo puede traer a la audiencia y leer anotaciones y otros documentos cuando se lo autorice y sea razonable para facilitar la declaración".

${ }^{76}$ Rule 31.16 (3) (d) Civil Procedure Rules.

${ }^{77}$ Jolowicz (2008), pp. 274-275.

${ }^{78}$ Rule 26 (b) (1) Federal Rules of Civil Procedure.

${ }^{79}$ DAMAŠKa (1997), p. 85.

${ }^{80} 192$ Conn. 138 (1984), citado en DAMAšKa (1997), pp. 85-86 n. 23.

${ }^{81}$ Para el contexto de la comunidad europea, véase PÉRez Ragone (2007), pp. 82-84, 93-94 y 16.2 Principios UNIDROIT: "Upon timely request of a party, the court should order disclosure of relevant, nonprivileged, and reasonably identified evidence in the possession or control of another party or, if necessary and on just terms, of a nonparty. It is not a basis of objection to such disclosure that the evidence may be adverse to the party or person making the disclosure".

${ }^{82}$ Rule 31.8 Civil Procedure Rules: “(1) A party's duty to disclose documents is limited to documents which are or have been in his control. (2) For this purpose a party has or has had a document in his control if- (a) it is or was in his physical possession; (b) he has or has had a right to possession of it; or (c) he has or has had a right to inspect or take copies of it". 
entiende por una "búsqueda razonable" también es señalado por la ley_ ${ }^{83}$ con el fin de ponerlo a disposición de quien lo reclama ${ }^{84}$. En este sentido, es que la jurisprudencia inglesa ha fallado

"que es un deber del representante acompañar la información relevante ante el tribunal incluso si su conocimiento resulta adverso a los intereses de su cliente" ${ }^{85}$.

Algo similar ocurre en Alemania con los documentos que uno de los litigantes tiene "en su poder" 6 .

En este orden de cosas, de los modelos que Rolf Stürner trazara en su tesis de habilitación para la Eberhard Karls Universität Tübingen en 1976, cuando examinó el deber de aclaración de los litigantes en el proceso civil (Die Aufklärungspflicht der Parteien des Zivilprozesses), uno de autoayuda y uno de cooperación ${ }^{87}$, la experiencia europea enseña que el segundo de ellos es el que se tiende a imponer. Para el Derecho moderno el acceso a la información relevante no se agota en lo que un litigante pueda comprar en el mercado de las pruebas, sino que, también, pasa por la cooperación de la contraparte y de los terceros con los fines que sirve la administración de justicia. Por cierto, el que el área de impacto -el hinterland- de la norma procesal penal que rechaza la autoincriminación -nemo tenetur contra se accusare- no alcance al proceso civil ${ }^{88}$, no implica que no existan excepciones a estos deberes (un ejemplo bastante conocido al respecto es el caso del documento que contiene una cláusula de confidencialidad).

En Chile, este compromiso con el acceso a la prueba también se registró desde temprano en el $C P C$. En cuanto a los terceros no interesados, por

${ }^{83}$ Rule 31.7 Civil Procedure Rules: "(1) When giving standard disclosure, a party is required to make a reasonable search for documents falling within rule 31.6 (b) or (c). (2) The factors relevant in deciding the reasonableness of a search include the following- (a) the number of documents involved; (b) the nature and complexity of the proceedings; (c) the ease and expense of retrieval of any particular document; and (d) the significance of any document which is likely to be located during the search".

${ }^{84}$ Véase CHOo (2009), pp. 59-60.

${ }^{85}$ Capeland v. Smith (2000) 1 WLR 1371, CA, citado en Andrews (2003), p. 46.

${ }^{86}$ \& 142.3 Zivilprozessordnung: "Orden de presentación de documentos. El tribunal puede ordenar que una parte o un tercero presente documentos u otros objetos que se encuentren en su poder, a los cuales una parte hizo remisión. El tribunal puede imponer un plazo y ordenar que la documentación permanezca por un determinado tiempo en la secretaría del tribunal".

${ }^{87}$ Se han tomado en cuenta los siguientes trabajos: STÜrner (2008), p. 244 y ss. y StÜrner (1981), 117 pp. Para un análisis más detenido de la litigación civil alemana: Murray \& StÜrner (2004) pp. 156-177.

${ }^{88}$ En sentido contrario se pronuncia GonZÁlez Coulon (2013), pp. 99-122, 139-142. 
ejemplo, se distinguieron varios supuestos: la exhibición de documentos ("con tal que tengan relación directa con la cuestión debatida y que no revistan el carácter de secretos o confidenciales”, art. 349 inciso $1^{\circ}$ ), la declaración de testigos (art. 380) y el peritaje (art. 420). En cualquiera de estos casos la persona reticente a colaborar podía ser multada o, en su defecto, arrestada. La colaboración de los litigantes, en tanto, tampoco estuvo ausente en la legislación de 1903, sobre todo si tenemos en cuenta lo que informó al respecto la jurisprudencia chilena. Así, por ejemplo, en Alarcón y otros con Empresa Constructora Emasil S.A., el juez ordenó como medida para mejor resolver (art. $159 \mathrm{del} C P C$ ) un peritaje, pero luego lo dejó sin efecto porque la demandada incumplió el pago del 50\% de los honorarios del perito que eran de su cargo y éste consideró que no valía la pena evacuar su informe. Frente a este escenario, la CS resolvió lo siguiente:

"Esta Corte entiende que los principios de lealtad de la contienda en que deben desarrollarse los procesos judiciales y la máxima cooperación con las labores del tribunal, puesto que es deber de las partes proporcionar los medios de prueba al juez, con el fin que emita fundadamente su decisión, circunstancia que impone a las partes prestar la mayor contribución que le sea posible" ${ }^{89}$.

En definitiva, es preciso advertir que en el campo de los hechos el deber de cooperación con el acceso a las pruebas no agota el sentido de la buena fe. En la comprensión moderna de la justicia son varias las figuras que apuntan en la misma dirección, pero dado que se trata de formas con un sello distintivo propio -como la facultad probatoria del tribunal o la renuncia a las pruebas ya ofrecidas- ${ }^{90}$, a pesar de su conexión interna con la buena fe procesal (de estar "implícitas" en ella, como dijera Eduardo Couture $)^{91}$, se trata de categorías que requieren de un análisis propio. El punto aquí es el siguiente: así como no es razonable "ver a la buena fe procesal en todos lados", tampoco puede negarse que ella funda una cooperación que ha contribuido al actual reparto de los papeles procesales y a que vivamos "en un mundo de híbridos" 92 . Sin ir más lejos (es una forma de decir, por supuesto), la reforma japonesa vigente desde 1998 también la introdujo al proceso civil ${ }^{93}$, pero al no haber regulado

${ }^{89}$ Alarcón y otros con Empresa Constructora Emasil S.A. (2008), cons. $17^{\circ}$ (destacados añadidos).

${ }^{90}$ Picó i Junoy (2013), pp. 175-182.

${ }^{91}$ Couture (2002), pp. 156-157.

92 Twining (2006), p. 196.

${ }_{93}$ Art. 2 Código Procesal Civil japonés (1996): "Courts shall endeavor to ensure that civil suits are carried out fairly and expeditiously, and parties shall conduct civil suits in good faith". 
sus aplicaciones en cuanto a la prueba generó confusión entre los sujetos a la hora de interpretar sus papeles en el juicio ${ }^{94}$. Como se ha señalado con anterioridad, parece que en el lenguaje de las cargas y los deberes existe una alternativa viable para que la legislación se haga cargo de estas dudas, tal como lo sugiere el Derecho Comparado en cuanto al acceso a las pruebas.

\section{2.b) El silencio de los demandados}

Lon Fuller habría aplaudido esta idea: la preclusión asegura la posibilidad de un juicio con las garantías del caso y mediante una inversión de recursos razonable ${ }^{95}$. Lo importante, para Lon Fuller, era la posibilidad de ir a juicio, a "una peculiar forma de participar" en la solución del conflicto caracterizada por la oportunidad de rendir las pruebas y los argumentos que favorecen los intereses de cada uno, así como de objetar la posición de la contraparte ${ }^{96}$. El viejo $C P C$, como otras leyes del siglo $\mathrm{xx}$, respondió a esta idea a través de un entramado de cargas y plazos fatales (art. 64) que impedían al tribunal enmendar lo hecho fuera de ellos (art. 84 inciso final), en una propuesta que confiaba el desarrollo del juicio a la rebeldía, o sea, a que el juez "provea lo que convenga para la prosecución del juicio" (art. 78). Lo que la rebeldía aseguraba era simplemente esto: que si una parte (interesada) no actuaba dentro del plazo (fatal) el juicio seguiría adelante (por impulso del tribunal). Ésta era, en el siglo Xx, la mejor forma de hacer realidad la preclusión. Lo relevante, entonces, es reparar en que la rebeldía no implicaba un blindaje para la parte que guardaba silencio y no actuaba dentro de plazo, pero por alguna razón nuestros jueces entendieron otra cosa cuando se trataba del silencio frente a una demanda. Para ese caso, los jueces vieron en el silencio una forma de rechazo a la pretensión del actor ${ }^{97}$.

El problema de esta lectura es que ella desalienta la participación de las partes en el debate jurídico. Para empezar, nótese que el $C P C$ nada dijo para el supuesto en que el demandado guardaba silencio en un juicio ordinario. Para el juicio sumario, en tanto, sus reglas fueron ambiguas, si bien se dispuso que "en rebeldía del demandado se recibirá la causa a prueba" (art. 684 inciso $1^{\circ}$ ), a renglón seguido la ley agregó: "el tribunal recibirá la causa a prueba, o citará a las partes para oír sentencia, según lo estime de derecho" (art. 685). Esto dio a pensar que en el sumario había dos posibilidades -"el que calla niega" o "el que calla otorga"- a elección

\footnotetext{
${ }^{94}$ Omura (1998), pp. 730-732.

${ }^{95}$ Por todos, véase: Gandulfo Ramírez (2009), p. 124.

${ }^{96}$ Fuller (1978), pp. 363-364, 371.

${ }^{97}$ Carrasco Poblete (2010), pp. 13-14.
} 
del juez, quien normalmente se inclinó por la primera, a pesar de todos los inconvenientes que ello suscitaba, los que pueden graficarse por medio del precario. En el precario, ante la no comparecencia del demandado a la audiencia de contestación y conciliación, los jueces optaron por recibir la causa a prueba en medio de serias interrogantes, como las que siguen: $\dot{c}$ al no decir nada el demandado, objetó la pretensión de dominio del actor?, ¿̇o lo que refutó fue la individualización del bien reclamado?, ¿tal vez negó su tenencia?, ċo calló porque se proponía justificar su tenencia por medio de un antecedente oponible al dueño? En fin, ¿̇por qué no pensar que en su silencio habitan todas estas posibilidades? ${ }^{98}$.

El punto aquí es que recibir la causa a prueba implica, para el $C P C$, una pieza esencial del juicio (art. $795 \mathrm{~N}^{\circ} 3$ ), porque con esta diligencia el juez fija los hechos sustanciales, pertinentes y controvertidos de la discusión (art. 318). La fórmula "silencio = negación" deviene, por lo tanto, un caso de abuso en el proceso -de origen judicial-si entendemos por abuso un comportamiento que afecta a los fines del proceso, no a sus medios. Aquí, el medio es la contestación de la demanda y su meta ("porque los procesos no se hacen con el solo fin de hacer procesos") ${ }^{99}$ es asegurar el derecho a defensa del demandado. Luego, si el fin del término de emplazamiento es garantizarle al demandado el tiempo necesario para su mejor defensa, este medio y la contestación ficta de la demanda tendrían que anticipar en lo posible aquel fin. Esto implicaría, en mi modo de ver, no fomentar la tesis de que el silencio (rebeldía) del demandado le provee de una coraza frente a la demanda y orientar la formación del debate hacia los deberes de colaboración, de modo tal de incentivar al demandado a que conteste la demanda (lo que implica, por cierto, cuidar algunos requisitos mínimos, como su acceso a una asesoría jurídica).

De allí que los documentos que informan la reforma civil chilena hayan sido criticados por albergar la idea de que "la rebeldía del demandado importará una negación de los hechos afirmados por el actor en su demanda" (art. 254 inciso $2^{\circ}$, Anteproyecto CPC 2006, art. 242, Proyecto CPC 2009 y art. 264, Proyecto CPC 2012), en una fórmula que, por lo demás, adolece de una seria inconsistencia interna, que fue notada desde temprano por Jaime Carrasco: sólo cuando se contesta la demanda "su silencio [del demandado], así como sus respuestas ambiguas o evasivas se tendrán como admisión de esos hechos" (art. 262 inciso $2^{\circ}$, Anteproyecto $C P C 2006)^{100}$. Este camino hace improbable la colaboración de las partes al momento en que se forma el debate, pues al demandado le podría con-

\footnotetext{
${ }^{98}$ LARroucau y Rostión (2013), pp. 73-74.

${ }^{99}$ Taruffo (2009), p. 301.

${ }^{100}$ Carrasco Poblete (2009), pp. 173-180.
} 
venir más no contestar la demanda, ya que sólo en el caso de contestarla quedará sujeto al deber de justificar su rechazo. Así lo expresa el art. 272 del Proyecto CPC 2012:

“Carga de controvertir los hechos afirmados en la demanda y los documentos acompañados por el actor y su sanción. En la contestación de la demanda deberá el demandado pronunciarse categórica y precisamente sobre la veracidad de los hechos alegados en la demanda y sobre la autenticidad, integridad y validez de los documentos que a ella se hubieren acompañado. (2) Su silencio, así como sus afirmaciones ambiguas o evasivas en la contestación podrán ser consideradas por el tribunal como admisión tácita de los hechos que le sean perjudiciales, así como admisión de la autenticidad, integridad y validez de los documentos acompañados".

La contestación de la demanda debe estar en sintonía con la buena fe procesal. Si alguien que ha sido debidamente notificado (y que tiene acceso a asesoría jurídica) decide no comparecer a juicio, no sólo es razonable que el juicio avance en su rebeldía -participación ficta- gracias a la preclusión sino que, también, es sensato disponer para él una consecuencia adicional ${ }^{101}$, algo que lo coloque en "una situación desventajosa"102. Ello es lo que ocurre en el Derecho Comparado, donde el silencio ante la acción incide en que se puedan tener por probados los hechos -vía inferencias procesales-, como en España ${ }^{103}$ o, bien, que se tengan por establecidos los hechos, como en Alemania ${ }^{104}$. La justicia del trabajo, en Chile, se inclinó por la primera de estas alternativas tras la reforma del año $2006^{105}$, mientras que desde hace décadas que el Código Procesal Civil Modelo para Iberoamérica invita a la segunda opción ${ }^{106}$. Es preciso observar también

${ }^{101}$ Véase Orellana y Pérez Ragone (2008), p. 11 y ss.

102 Carretta Muñoz (2008), p. 107.

${ }^{103}$ Art. 405 inciso $2^{\circ}$ Ley de Enjuiciamiento Civil: "En la contestación a la demanda habrán de negarse o admitirse los hechos aducidos por el actor. El tribunal podrá considerar el silencio o las respuestas evasivas del demandado como admisión tácita de los hechos que le sean perjudiciales".

${ }^{104}$ § 331.1 Zivilprozessordnung. "En caso de que el actor solicite sentencia en rebeldía en contra del demandado incompareciente en término a la audiencia, deben tenerse por admitidas las alegaciones del actor respecto de los hechos".

${ }^{105}$ Art. 453 N 1.7 Código del Trabajo: "Cuando el demandado no contestare la demanda, o de hacerlo no negare en ella algunos de los hechos contenidos en la demanda, el juez, en la sentencia definitiva, podrá estimarlos como tácitamente admitidos".

${ }^{106}$ Art. 299 inciso $4^{\circ}$ Código Procesal Civil Modelo para Iberoamérica: "La rebeldía del demandado determinará que el Tribunal deba tener por admitidos los hechos alegados por el actor, en cuanto no resultaren contradichos por la prueba de autos, la que deberá igualmente ser diligenciada, en todo lo que el Tribunal considere necesario". 
que el Proyecto CPC 2012 llamó carga a una regla que formuló como un deber (en su análisis de la Ley de Enjuiciamiento CivilDiego Palomo también califica de carga a la contestación de la demanda, aunque allí el silencio del demandado puede acarrearle una consecuencia desfavorable, adicional a la preclusión, de modo que tendría que asumirse como un deber al menos bajo la nomenclatura que sigue este trabajo ${ }^{107}$. Es cierto que desde un punto de vista conceptual puede distinguirse entre la carga de comparecer-el demandado decide si concurre o no al tribunal-y el deber de fundamentar su contestación -no depende del demandado si justifica o no su respuesta-, pero en la práctica esta distinción se difumina porque se comparece contestando (a menos que se cultive una idea mínima de comparecencia en términos de que para comparecer bastaría con notificarse y con haberle otorgado un mandato a un abogado). Por lo tanto, la regla del Código Procesal Civil tiene que disponer como un deber del demandado el de contestar la demanda (y justificar su rechazo) o atenerse a ciertas consecuencias.

Antes de cerrar esta parte, valga una advertencia: lo dicho no significa que la preclusión no sirva por sí sola como forma de modelar las conductas procesales. Por el contrario, existe una legítima inquietud en torno a que en ciertos casos la preclusión podría limitar demasiado el derecho a defensa, temor que se puede graficar con dos ejemplos. Primero, una regla que es típica de los juicios por audiencias -la exigencia de acompañar las pruebas al comienzo del proceso- podría ser muy rigurosa con algunas pruebas de gran peso -como los documentos- que no se acompañaron en el primer escrito ${ }^{108}$. El momento en que las partes deben señalar sus pruebas se vincula con el estándar de admisibilidad de esa información, el cual debería ser sensible a este punto ${ }^{109}$. El segundo caso, en tanto, alude a una práctica local de los tribunales chilenos: declarar el desistimiento del recurso de casación cuando no se acompañan las compulsas. Este modo de leer el art. 776 del $C P C$ ha sido resistido con las siguientes palabras:

"una simple regla técnica (dejar dinero para compulsas) no puede prevalecer sobre la garantía constitucional del debido proceso, cuyo contenido básico pasa por garantizar a los justiciables el derecho a los recursos" ${ }^{\prime 10}$.

${ }^{107}$ Palomo Vélez (2008), p. 157.

${ }^{108}$ Para el caso italiano: Monteleone (2007), p. 121 y ss; para el caso peruano: Ariano (2007), p. 621 y ss.

${ }^{109}$ Véase Larroucau Torres (2012b), p. 185 y ss.

${ }^{110}$ Romero Seguel (2000), p. 419. 
Sin olvidar que la preclusión se expresa a través de esas "simples reglas técnicas", no es menos cierto que algunas de sus aplicaciones pueden mermar el derecho de defensa, por lo que se vuelve necesario distinguir entre grupos de casos, de modo que la hipótesis del litigante que acompaña un documento después de contestada la demanda (habría que ver cómo se justifica dicho retraso) y el caso de la persona que no paga a tiempo las copias del recurso, puedan quedar sujetos a reglas diferentes.

\section{LAS SANCIONES}

En su prólogo al trabajo de la International Association of Procedural Law, publicado tras la cita del año 1998 en New Orleans, Marcel Storme dijo que hablar de abuso de los derechos procesales "es una típica cuestión fin-de-siècle" y que el nuevo milenio -el nuestro- se caracterizaría por una constante búsqueda del homo novus processualis, en una pesquisa que sería "una cuestión de formación y también de educación jurídica, pero no de nuevas normas legales, salvo por las sanciones". ${ }^{111}$ El Proyecto CPC 2012 parece a primera vista un texto inmerso en esa búsqueda, por cuanto postula que "el tribunal, de oficio o a petición de parte, deberá prevenir, 290 corregir y sancionar, según corresponda" (art. 5) las infracciones a la buena fe procesal. La prevención, como es sabido, suele expresarse en el lenguaje de las cargas procesales, pues la preclusión implica que una conducta contraria a la buena fe no será admitida en el juicio (así, por ejemplo, no se puede oponer una excepción dilatoria fuera de plazo); la corrección, en tanto, se vincula con el manejo del caso que tiene el tribunal -un aspecto donde la experiencia inglesa es un referente ineludible- ${ }^{112}$ y un poder que va desde moderar los alegatos de los abogados hasta detectar vicios de nulidad que afecten al juicio y, por último, la sanción, que pareciera ser la pieza más delicada del modelo normativo que propone la buena fe para la litigación moderna y sobre la cual me concentro en lo que resta de este trabajo.

La sanción puede ser económica (como una suma de dinero que va a la cuenta corriente del tribunal) o puede afectar de un modo más evidente la libertad de alguien (como en el arresto); pero, sea cual sea su intensidad, esta figura plantea al menos tres problemas importantes:

a) por un lado, el asunto de la tipificación de las cargas y los deberes (la pregunta por las 'jugadas posibles' y las 'jugadas correctas' en la litigación);

${ }^{111}$ Taruffo (ed.) (1999), p. xiii.

112 Part 3 The Court's Case Management Powers, Civil Procedure Rules. 
b) por el otro, la (in)determinación de las sanciones -que puede llevar a una "eficacia disminuida" de los deberes procesales- ${ }^{113} \mathrm{y}$

c) por último, la pregunta por el procedimiento empleado para imponer estas medidas.

Cada uno de estos puntos contiene sus propios desafíos y una legislación atenta a los fines del esfuerzo judicial debería dar cuenta de ellos.

A efectos de explorar cada uno de estos temas téngase en cuenta un común denominador de la buena fe procesal: sea que se trate de prevenir, corregir o sancionar, ella implica modelar conductas y no (sólo) sugerir modos de comportamiento. Es decir, no es algo así como un soft law: ella reclama una adhesión no por gentileza de quienes participan en el juicio, sino que en conformidad a un interés público. Este interés queda de manifiesto, sobre todo, en las sanciones (nótese que las multas se imponen a beneficio fiscal), de modo que de su adecuado funcionamiento depende gran parte del éxito de la buena fe procesal, donde el éxito se mide por la efectividad en hacer común esta idea de que sus normas no son consejos que orientan decisiones, sino que reglas de conductas que hacen probable el cumplimiento de los fines que sirve la administración de justicia.

\section{El problema de la tipicidad de los comportamientos}

La especificidad de las conductas que promueve la buena fe es un desafío importante para la literatura procesal. Esto es así desde que el Mensaje del $C P C$ hiciera su mención a

"una serie de medidas encaminadas a hacer ineficaces los expedientes dilatorios a que apela la mala fe para retardar la solución de los pleitos".

Como se recordará, la legislación procesal civil de 1903 sólo precisó este umbral para ciertos casos, como fue el de los incidentes (para aumentar la cuantía del depósito, art. 88), las implicancias (por el retardo malicioso en su reclamo, art. 114 inciso $2^{\circ}$ ) y en el término probatorio extraordinario (si había "justo motivo para creer que se pide maliciosamente con el solo propósito de demorar el curso del juicio", art. 330). Algo más de un siglo después, los votos por un Código Procesal Civil no variaron demasiado las cosas, al dejar el asunto expuesto a un marco de comportamiento amplio; en efecto, los actos procesales deben ser "lícitos, pertinentes y útiles" (art. 62 del Proyecto CPC 2012) y, salvo algunos casos típicos (similares a los de 1903), no se añade información acerca de cuándo un acto supone un

${ }^{113}$ Carretta (2008), p. 120. 
abuso o un entorpecimiento. El Proyecto CPC 2009 (art. 61), recogiendo una idea del Anteproyecto CPC 2006 (art. 71), había dispuesto que los actos procesales, además de "lícitos, pertinentes y útiles", fuesen ejecutados "con veracidad, buena fe" y "un interés legítimo", pero el Proyecto CPC 2012 desestimó este camino, probablemente porque las categorías de licitud, pertinencia y utilidad son tan amplias que incluían a estas otras.

Este artículo promueve la idea de que para conocer los márgenes de las actuaciones procesales la fisonomía de las cargas y los deberes supone un camino auspicioso. En muchos casos el supuesto de hecho de la carga o del deber es relativamente fácil de identificar: así, por ejemplo, el abogado que se anuncia para alegar ante una Corte de Apelaciones puede ser multado por el presidente de la Sala si no concurre a alegar (y mientras no pague la multa no podrá comparecer ante esa Corte, art. 223 inciso quinto, CPC) o, bien, el caso de la responsabilidad civil por no interponer la demanda en el plazo legal una vez que se consigue una medida cautelar precautoria prejudicial (art. 280 del CPC). Pero también es cierto que, en otros casos, a pesar de esta distinción entre cargas y deberes subsiste el problema de la indeterminación de la conducta, como ocurre con la facultad de los tribunales para "la represión o castigo de las faltas de respeto que se cometieren en los escritos" (art. 531, Código Orgánico de Tribunales) en el caso de 292 "palabras o pasajes abusivos", conductas que pueden dar lugar a una multa $\mathrm{o}$, incluso, a la suspensión del ejercicio de la profesión por un mes ${ }^{114}$. Para estos últimos casos es que el cultivo de cánones de interpretación en torno a la buena fe resulta primordial. A este respecto, me parece que la literatura procesal chilena tendría que emular la actitud interpretativa del Derecho Civil, donde con prudencia y gracias a un permanente esfuerzo interpretativo en lo que se refiere a los supuestos de aplicación, la jurisprudencia le ha reconocido como una fuente de deberes no explicitados ${ }^{115}$, tanto en lo que se refiere a las precauciones que se adoptan cuando se adquiere un bien (propiedad) como a propósito de las conductas ventajosas que son admisibles durante una negociación (contrato) ${ }^{116}$. Otro tanto ha ocurrido en los últimos años con el Derecho del Trabajo chileno ${ }^{117}$.

La tesis más que mínima de la buena fe procesal fomenta este ejercicio de especificación de las conductas, donde un ejemplo del camino a seguir lo provee el Código de Ética, elaborado por el Colegio de Abogados de Chile (para ser más precisos: Santiago de Chile) y vigente desde el año

${ }^{114}$ Art. 79, Proyecto CPC 2012: "Podrá el tribunal mandar a devolver un escrito con orden que no se admita mientras no se supriman las palabras ofensivas o pasajes abusivos".

${ }^{115}$ Corral Talciani (2006), pp. 200-205.

${ }^{116}$ Desde un punto de vista comparado y económico, véase MACKAAY (2012, p. 149 y ss.

${ }^{117}$ Irureta Uriarte (2011), pp. 148-175. 
2011. Para este Código de Ética, todo abogado tiene un deber de "apoyo a la Magistratura" (art. 93), lo cual implica "lealtad en la litigación" (art. 95) 118 y "observar de buena fe" las reglas del juicio (art. 96) ${ }^{119}$. Según se ve, una

${ }^{118}$ Art. 95 Código de Ética: "Lealtad en la litigación. El abogado litigará de manera leal, velando por que su comportamiento no afecte o ponga en peligro la imparcialidad del juzgador, ni vulnere las garantías procesales y el respeto debido a la contraparte.

En razón de este deber, está prohibido al abogado:

a) generar condiciones para obtener un trato preferencial por los jueces llamados actual o potencialmente a decidir la cuestión debatida;

b) influir en el tribunal apelando a razones políticas, de amistad u otras que no se vinculen exclusivamente con los antecedentes relevantes en el caso;

c) tratar de influir en los jueces solicitando o participando en audiencias no previstas por las reglas procesales vigentes y que alteren el principio procesal de bilateralidad; podrá el abogado excepcionalmente solicitar al tribunal tales audiencias si los procedimientos no cautelan suficientemente el derecho de una parte a ser escuchada, o bien cuando sean especialmente dañosas las consecuencias que se pudieren seguir del retardo en el conocimiento por el tribunal de ciertas circunstancias del caso;

d) ofrecer o dar beneficios a funcionarios que intervengan en un proceso judicial, sea en forma de regalos de cualquier naturaleza y monto, sea pagando por servicios que no son remunerados, sea haciéndolo en exceso aquéllos que son naturalmente remunerados;

e) presentar pruebas a sabiendas de que son falsas u obtenidas de manera ilícita;

f) instruir a testigos, peritos o al cliente para que declaren falsamente. Lo expresado no obsta a que pueda entrevistarlos respecto de hechos relativos a una causa en que intervenga, o que recomiende al cliente guardar silencio en audiencias de prueba o en la etapa de investigación cuando así lo autorizan las normas legales aplicables;

g) destruir o impedir el acceso a piezas de información relevantes para un caso y a cuyo respecto haya deber legal o convencional de aportar al proceso, ya sea directamente o bien instruyendo o instando al cliente o a terceros para que lo hagan;

h) ofrecer o dar compensaciones económicas a testigos que vayan más allá de los costos que deben asumir para prestar su testimonio, o bien, que se hagan depender tales compensaciones del beneficio que pudiere representar la declaración para los intereses del cliente;

i) hacer depender la remuneración de los peritos de que las conclusiones de su informe sean favorables a los intereses del cliente o de las resultas del pleito;

j) utilizar en los juicios antecedentes respecto de los cuales hubiere confidencialidad, según lo dispuesto en el artículo 110;

k) violar los acuerdos que hayan sido adoptados con la contraparte. En particular, el abogado no sacará ventajas de la indefensión de la contraria que ha confiado en el cumplimiento de un acuerdo relativo a la manera u oportunidad en que se realizaría cierta actuación procesal”.

${ }^{119}$ Art. 96 Código de Ética: "Respeto a las reglas de procedimiento. El abogado observará de buena fe las reglas procesales establecidas por la ley o por la convención entre las partes y no realizará actuaciones dirigidas a impedir que la contraparte ejerza debidamente sus derechos.

En especial, está prohibido al abogado:

a) aconsejar o ejecutar maniobras que constituyan un fraude procesal, como presentar documentos en que se haga aparecer como cumplida una actuación judicial que en verdad no se ha realizado; 
lista de compromisos como ésta tendría que discutirse como parte de las reglas del Código Procesal Civily del Código Orgánico de Tribunales, ya que, como se reitera, la buena fe procesal no se agota en su faz negativa, de prohibiciones y abstenciones, sino que, también, tiene un aspecto positivo, de normas que impulsan algunas conductas y que ameritan un nivel de detalle similar al que propone este Código de Ética. Bajo una tesis más que mínima, la buena fe precisa de un anclaje normativo más o menos diáfano a efectos de moldear las relaciones procesales sobre la base de una idea de reciprocidad, según cuál sea la posición que ocupa cada uno de los intervinientes en el juicio. Esto se puede ejemplificar brevemente con la esfera institucional del tribunal.

En el caso del juez, cabe distinguir dos tipos de deberes:

i) sus deberes en el proceso, como el de resolver los conflictos "tan pronto como estén en estado" (art. 162 del CPC), que se expresa en una obligación

("los jueces están obligados a despachar los asuntos sometidos a su conocimiento en los plazos que fija la ley o con toda la brevedad que las actuaciones de su ministerio les permitan",

art. 319 del Código Orgánico de Tribunales) cuyo incumplimiento podría hacerlo responsable civilmente, según Eduardo Couture ${ }^{120}$ y

ii) sus deberes en la administración de justicia: tanto los deberes que se refieren a su residencia y horario de trabajo, como los que neutralizan posibles conflictos de intereses o inhabilidades, y los que definen algunos de sus derechos civiles y políticos más importantes (art. 311 a 323 ter del Código Orgánico de Tribunales), junto con los que determinan su responsabilidad penal y civil (art. 324 a 331 del Código Orgánico de Tribunales) ${ }^{121}$.

La arquitectura normativa de estos deberes va a depender, por supuesto, de la respuesta a una cuestión previa acerca de qué es lo que esperamos de un juez, un asunto complejo, sin duda, sobre el cual no parece haber consenso: así, por ejemplo, aunque existen buenas razones para entender que un juez también puede ser un agente del abuso al momento en que

b) burlar los mecanismos aleatorios previstos en los procedimientos judiciales para la distribución de causas, la asignación de salas u otros similares;

c) adulterar la fecha u hora de presentación o recepción de escritos;

d) abusar de la facultad de interponer recursos o incidentes judiciales, en especial si por esos medios se buscare provocar daño injusto a la contraparte o forzarla a celebrar un acuerdo gravoso".

${ }^{120}$ Couture (2002), p. 64.

${ }^{121}$ Carretta Muñoz (2012), p. 325 y ss. 
ordena una medida cautelar ${ }^{122}$, la tendencia en la reforma a la justicia chilena es la de blindarlo de responsabilidad en este ámbito y reconducir los problemas a la parte que solicita la medida (art. 177 del Anteproyecto CPC 2006; art. 168 del Proyecto CPC 2009; art. 177 del Proyecto CPC 2012). Con esto parece que se honra una tradición del Código Orgánico de Tribunales, que tiende a eximir a los jueces de una posible responsabilidad por sus decisiones (art. 13), aunque es razonable pensar que un tribunal que persistentemente se equivoca en sus decisiones, al menos, pone en entredicho su imparcialidad.

\section{El problema de la (in)determinación de las sanciones}

La incertidumbre acerca de los supuestos de hecho de las cargas y los deberes alcanza también a las consecuencias jurídicas que acarrea defraudar la buena fe procesal. Este segundo desafío -la indeterminación de las sanciones- debería ser abordado mediante un marco sancionatorio general como el que propuso el Anteproyecto CPC 2006, en los incisos 3 y 4 de su art. 8:

"Si los tribunales estimaren que alguna de las partes o terceros han actuado conculcando las reglas de la buena fe procesal, podrán imponerle, de forma motivada, y respetando el principio de proporcionalidad, una multa entre 10 y 100 UTM. En ningún caso la multa podrá superar la tercera parte de la cuantía del litigio. En caso de reincidencia, se podrá aplicar el doble de la multa. (4) Para determinar la cuantía de la multa el tribunal deberá tener en cuenta las circunstancias de hecho que se trate, así como los perjuicios que al procedimiento o a las otras partes se hubieren podido causar".

A pesar de que el propio Anteproyecto CPC 2006 no estuvo exento de incoherencias internas en cuanto a las sanciones (en ciertos casos había superposición de medidas y en otros una desproporción entre la conducta y su secuela) ${ }^{123}$, el que se prescindiera de este marco supletorio -que se tomó probablemente de la Ley de Enjuiciamiento Civil española (art. 247.3)-, tanto en el Proyecto CPC 2009 como en el Proyecto CPC 2012, agudiza la cuestión de qué ocurre con las conductas respecto de las cuales la legislación no contempla una sanción específica. Nótese que el Proyecto CPC 2012 sólo consideró aquellas conductas más notorias, como la de incumplir una medida cautelar (para

${ }^{122}$ En este sentido: Tavolari Oliveros (2002), pp. 105-113.

${ }^{123}$ Gorigoitía (2008), pp. 150-151. 
"imponer multas sucesivas que no excedan de dos unidades tributarias mensuales o arrestos de hasta treinta días, determinados prudencialmente por el tribunal”,

art. 168) y uno que otro caso novedoso (en Chile) como la condena en costas al abogado que incurre "reiteradamente en acciones manifiestamente dilatorias" (art. 45), pero quedó en el aire qué ocurre con todas las demás hipótesis, donde tal vez la infracción a la buena fe se queda sin sanción si entendemos que el principio de legalidad nos exige que la sanción esté establecida de antemano ${ }^{124}$.

Para avanzar en este punto cabe observar, en primer lugar, que la literatura comparada converge en que es necesaria una regla expresa si la sanción que se impone es una multa ${ }^{125}$. Lo que el Derecho Comparado cuida, en el fondo, es que la sanción sea proporcional a la conducta (por todos, véanse los Principios UNIDROIT: "Las sanciones deben ser razonables y proporcionales a la seriedad de la materia respectiva", 17.2). Para que el juez cuente con parámetros mínimos que le permitan medir esta proporcionalidad la Ley de Enjuiciamiento Civil española, por ejemplo, exigió que se considerasen las circunstancias del caso y los daños sufridos, tanto por el juicio como por la contraparte, además de fijar unos límites 296 en cuanto al monto: la multa en España puede oscilar entre €180 y €6.000, pero nunca exceder un tercio de lo que se disputa (art. 247 inciso $3^{\circ}$ ). En Francia, en tanto, quienes obren de un modo que sea abusivo o dilatorio pueden ser multados hasta con $€ 3.000$ y sin perjuicio de la eventual responsabilidad civil que se les pudiere probar ${ }^{126}$.

La ponderación de intereses que reclama esta proporcionalidad no siempre es formulada de modo explícito por una regla (como ocurre, por ejemplo, en la Ley del Consumidor, donde se considera causal de disolución de las organizaciones que defienden los derechos de los consumidores el que ellas sean condenadas por litigación temeraria) ${ }^{127}$, motivo por el cual parece necesario volver a reflexionar sobre la fórmula del Anteproyecto $C P C$ 2006 y su marco sancionatorio general. El punto aquí es procurar que no ocurra con la justicia civil lo mismo que pasó con la justicia del trabajo,

${ }^{124}$ En este sentido Larroucau García (2010), p. 78.

${ }^{125}$ Por todos Cachón Cadenas (2006), pp. 225-243.

${ }^{126}$ Art. 32-1 Code de Procédure Civil: "Celui qui agit en justice de manière dilatoire ou abusive peut être condamné à une amende civile d'un maximum de 3.000 euros, sans préjudice des dommages-intérêts qui seraient réclamés".

${ }^{127}$ Art. 7.2 ley $\mathrm{N}^{\mathrm{O}}$ 19.496: "En caso de que el juez, dentro del plazo de tres años, declare temerarias dos o más demandas colectivas interpuestas por una misma Asociación de Consumidores, podrá, a petición de partes, en casos graves y calificados, decretar la disolución de la asociación, por sentencia fundada”. 
donde la idea de incluir una sanción genérica de 15 UTM no prosperó ${ }^{128}$. También éste podría ser el momento propicio para debatir acerca de otras formas de desincentivar los comportamientos no deseados en la litigación. Se mencionan solamente tres de las ideas que se han barajado:

i) una acción revocatoria similar a la acción pauliana de la contratación (art. 2468 del CC) para atacar al fallo dictado en un juicio fraudulento, aunque la sentencia tenga fuerza de cosa juzgada ${ }^{129}$ (habría que discutir si el mismo fin podría lograrse mediante el recurso de revisión, si se amplía el plazo para interponerlo y se precisa lo que debemos entender por un juicio ganado "injustamente en virtud de cohecho, violencia u otra maquinación fraudulenta", art. $810 \mathrm{~N}^{\circ} 3$ del $C P C$ );

ii) las costas procesales y su nexo con las conductas de los sujetos procesales (recuérdese que según el $C P C$ "sólo se tasarán las costas procesales útiles", art. 140) y

iii) la nulidad procesal, porque el acto que sufre de "un vicio que irrogue a alguna de las partes un perjuicio reparable sólo con la declaración de nulidad" (art. 83 inciso $1^{\circ}$ ) toca un punto que es aledaño a la buena fe, sobre todo cuando la nulidad es vista como una forma de dar protección a ciertos bienes -más que como una sanción-y se delibera acerca de los modelos que dirimen, primero, la irregularidad del acto y, luego, su declaración de invalidez e ineficacia ${ }^{130}$.

\section{El problema del procedimiento}

Finalmente, las sanciones o medidas que se impongan por infringir la buena fe procesal deben dictarse en virtud de un procedimiento que cumpla con un mínimo de garantías. Así, la decisión del juez debe ser fundada o motivada (por todos: Ley de Enjuiciamiento Civil española, art. 247 inciso 2) y los involucrados deben tener la oportunidad de contradecir sus posiciones, aunque sea en un procedimiento incidental ${ }^{131}$. Estas dos garantías -contradicción y motivación- pueden servir para custodiar que las medidas sean proporcionales a la conducta del infractor, sobre todo cuando se impone una multa (aunque las multas en Chile no necesariamente deben entenderse como una pena, art. 20 del Código Penal). También es adecuado pensar en otros aspectos, como la posibilidad de recurrir en contra de estas medidas (por ejemplo, ante la Corte de Ape-

\footnotetext{
${ }^{128}$ Larroucau García (2010), p. 69 n. 10.

${ }^{129}$ Ello ha sido propuesto en Pacheco Valderrama (1995), p. 148.

${ }^{130}$ En este sentido Carrasco Poblete (2011), p. 49 y ss; Gorigoitía Авott (2013), p. 129 y ss.

${ }^{131}$ Hunter (2008), pp. 177-178.
} 
laciones respectiva en el caso de multas y apremios; ante el mismo juez en los demás supuestos) y una deferencia con el crédito del actor cuando a la contraparte se le impone una multa (debido a que el importe va en beneficio fiscal) ${ }^{132}$.

Y para concluir, una última pregunta: cंconviene tramitar conjuntamente la imposición de estas sanciones con una eventual responsabilidad civil de quien ha infringido la buena fe procesal? Tanto el Anteproyecto $C P C$ 2006 (art. 56), como el Proyecto CPC 2009 (art. 47) y el Proyecto CPC 2012 (art. 50) han descartado esta posibilidad: ante un "proceder de mala fe o temerario" el vencedor (¿ por qué solo él?) puede reclamar -en un plazo de seis meses y en un juicio sumario- los daños indemnizables, sin que el juez pueda fijar en el mismo fallo los perjuicios, como sí se permite en Italia $^{133}$ y Colombia ${ }^{134}$.

\section{Conclusiones}

La buena fe procesal es una pieza clave para una administración de justicia moderna. En su calidad de cláusula abierta admite más de una lectura. En las páginas anteriores se exploraron tres tesis conceptualmente distintas para dotarla de contenido normativo, con el propósito de elaborar un mapa o carta de navegación que oriente la toma de decisiones por parte de los sujetos procesales.

Las principales conclusiones son:

1) Las diversas interpretaciones que admite la buena fe procesal se pueden reconducir a tres: una tesis fuerte (contribuir a la solución justa del caso), una lectura mínima (no litigar con dolo) y una concepción más que mínima (cumplir con ciertos deberes y cargas procesales);

2) La lectura fuerte defiende al menos tres deberes para la posición del litigante: una "máxima colaboración" (en el acceso a las prue-

${ }^{132}$ Picó i Junoy (2013), pp. 317-334.

${ }^{133}$ Art. 96 Codice di Procedura Civile: "Se risulta che la parte soccombente ha agito o resistito in giudizio con mala fede o colpa grave, il giudice, su istanza dell'altra parte, la condanna, oltre che alle spese, al risarcimento dei danni, che liquida, anche d'ufficio, nella sentenza".

${ }^{134}$ Art. 80 inciso $1^{\circ}$ Código General del Proceso: "Responsabilidad patrimonial de las partes. Cada una de las partes responderá por los perjuicios que con sus actuaciones procesales temerarias o de mala fe cause a la otra o a terceros intervinientes. Cuando en el proceso o incidente aparezca la prueba de tal conducta, el juez, sin perjuicio de las costas a que haya lugar, impondrá la correspondiente condena en la sentencia o en el auto que los decida. Si no le fuere posible fijar allí su monto, ordenará que se liquide por incidente”. 
bas), 'decir la verdad' (en relación con los hechos) y no contradecir sus propios actos (en el debate jurídico). La tesis fuerte exagera la extensión de estos deberes, pero acierta en darles esa calificación (salvo en el caso de la verdad de los hechos);

3) La lectura mínima entiende la buena fe procesal como una forma de neutralizar el dolo, pero abre la puerta a la discrecionalidad judicial, por dos razones: prescinde de un marco regulatorio amplio que permita identificar las conductas que deben ser consideradas y no provee de los cánones interpretativos necesarios para saber cuándo un sujeto actúa con dolo (o alguna de las categorías que esta lectura considera equivalentes);

4) La buena fe procesal es un principio en un sentido doble: se refiere al comportamiento de todos quienes intervienen en un juicio (las partes, los terceros y el tribunal) y abarca todas las dimensiones del juicio (cautelar, declarativa o ejecutiva), no obstante lo cual este artículo sugiere abandonar su análisis como principio -como algo que inspira a la justicia-y dar paso a una reflexión normativa donde la buena fe se conecta con la minimización de los riesgos de error que entraña el hecho de que el juez censure o admita una determinada conducta en el proceso;

5) La tesis más que mínima entiende que la buena fe procesal debe hacer explícitos los márgenes de acción de los intervinientes en el juicio mediante cargas y deberes procesales -como el de colaborar con el acceso a las pruebas o el de fundamentar la contestación de la demanda- cuya proporción va a depender de los intereses que sean protegidos en cada caso;

6) Las sanciones por infringir la buena fe deben ser proporcionales a la conducta que se evalúa. La aplicación de estas medidas da lugar a ciertos desafíos (tipicidad, indeterminación, procedimiento) de los que la legislación procesal tiene que hacerse cargo.

En definitiva, debo reiterar algo que fue dicho desde el comienzo de este artículo: es difícil pensar la buena fe procesal sin una idea previa de la jurisdicción. En cierto modo, estas tres tesis evocan una imagen de lo que debe ser un juicio y un juez. Quizá esta pluralidad de enfoques sea una fortaleza más que una debilidad y la competencia entre ellos represente algo saludable para la administración de justicia, de modo tal que interpretar la buena fe procesal no sería más que otra búsqueda del justo medio; o -en el aforismo de Arthur Schnitzler- una nueva constatación de que "todo intento de llevar a la práctica una idea hasta sus últimas consecuencias es una prueba de que no se la ha entendido". 


\section{Bibliografía CITADA}

Alexander, Larry (1998). "Are Procedural Rights Derivative Substantive Rights?". Law and Philosophy. vol. 17, Netherlands.

Allen, Ronald y Michael Pardo (2003). "The Myth of the Law-Fact Distinction". Northwestern University Law Review. vol. 97, $\mathrm{N}^{\circ}$ 4, Illinois.

Andrews, Neil (2003). English Civil Procedure. Fundamental of the New Civil Justice System. Oxford: Oxford University Press.

"Anteproyecto de Código Procesal Civil" (2006). Revista de Estudios de la Justicia, $\mathrm{N}^{\mathrm{o}}$ 8, Santiago.

ARIANo, Eugenia (2007). "Las preclusiones probatorias en el proceso civil peruano 'publicizado"”, en Andrés de la Oliva y Diego Palomo (coords.), Proceso civil. Hacia una nueva justicia civil. Santiago: Editorial Jurídica de Chile.

Atria Lemaitre, Fernando (2002). "The Power of Application”, Ratio Juris, vol. $15, \mathrm{~N}^{\circ} 4$, Malden.

Barros Bourie, Enrique (2006). Tratado de responsabilidad extracontractual. Santiago: Editorial Jurídica de Chile.

Bentham, Jeremy (2001), Tratado de las pruebas judiciales, obra compilada de los manuscritos del autor por E. Dumont, traducción del francés por Manuel Ossorio Florit, Granada: Editorial Comares.

Bone, Robert (2008). "Making Effective Rules: The Need for Procedure Theory". Oklahoma Law Review, vol. 61. Oklahoma.

Bordalí, Andrés y Juan Carlos MARÍn (2005). "Las relaciones entre las partes, los jueces y los abogados. El caso de Chile”, en Marcel Storme y Cipriano Gómez (coords.), XII Congreso Mundial de Derecho Procesal. México D.F.: UNAM, vol. III.

Bordalí Salamanca, Andrés (2011). "Análisis crítico de la jurisprudencia del Tribunal Constitucional sobre el derecho a la tutela judicial". Revista Chilena de Derecho. vol. 38, No 2, Santiago.

Cabrillo, Francisco \& Sean FitzPatrick (2008). The Economics of Courts and Litigation. Cheltenham/Northampton: Edward Elgar.

Cachón Cadenas, Manuel (2006). "La buena fe en el proceso civil". Cuadernos de Derecho Judicial, vol. xviII, Madrid.

Calvo Soler, Raúl (2003). Uso de normas jurídicas y toma de decisiones. Barcelona: Editorial Gedisa.

CaPPALLI, Richard (1992). "Procedimiento civil comparado: Estados Unidos, Chile y Sudamérica”. Revista Chilena de Derecho. vol. 19, No 2, Santiago.

Carrasco Poblete, Jaime (2011). "La nulidad procesal como técnica protectora de los derechos y garantías de las partes en el derecho procesal chileno". Revista de Derecho, vol. 18, No 1, Coquimbo.

Carrasco Poblete, Jaime (2010). La rebeldía en los procesos civil y laboral. Santiago de Chile: AbeledoPerrot. 
Carrasco Poblete, Jaime (2009). "La rebeldía en el Anteproyecto de Código Procesal Civil". Cuadernos de Extensión Jurídica, No 16, Santiago.

Carretta Muñoz, Francesco (2013). La coherencia en el proceso civil: Imperativo conductual y decisional desde la buena fe (Casos y jurisprudencia), en proceso de publicación

Carretta Muñoz, Francesco (2012). "La simetría de la relación adjetiva civil y el abuso procesal de los jueces”. Revista de Derecho, vol. XxxviII, Valparaíso.

Carretta Muñoz, Francesco (2008). "Deberes procesales de las partes en el proceso civil chileno". Revista de Derecho, vol. XXI, $\mathrm{N}^{\circ} 1$, Valdivia.

Cipriani, Franco (2006). "El abogado y la verdad", en Juan Montero Aroca (coord.), Proceso civil e ideología. Un prefacio, una sentencia, dos cartas y quince ensayos. (Trad.) Eugenia Ariano Deho. Valencia: Tirant lo Blanch.

Coloma Correa, Rodrigo (2006). "Vamos a contar mentiras, tralará..., o de los límites a los dichos de los abogados". Revista de Derecho, vol. xIX, N 2 . Valdivia.

Contardo GonzÁlez, Juan Ignacio (2010). "La doctrina de los actos propios en la jurisprudencia civil chilena”, en Hernán Corral (ed.), Cuadernos de Extensión. $\mathrm{N}^{\mathrm{o}}$ 18: Venire contra factum proprium. Escritos sobre la fundamentación, alcance y límites de la doctrina de los actos propios. Santiago.

CORRAl TAlCIANI, Hernán (2006). "La aplicación jurisprudencial de la buena fe objetiva en el ordenamiento civil chileno”. Cuadernos de Análisis Jurídico. Santiago. vol. III.

Couture, Eduardo (2010). Fundamentos del derecho procesal civil. $4^{\mathrm{a}}$ ed., MontevideoBuenos Aires: Editorial B de F, $4^{\mathrm{a}}$ reimpresión.

Chase, Oscar (2011). Derecho, cultura y ritual. Sistemas de resolución de controversias en un contexto intercultural. (Trad.) Fernando Martín Diz. Marcial Pons, MadridBarcelona-Buenos Aires.

Choo, Andrew L-T (2009). Evidence. $2^{\text {a }}$ ed. Oxford: Oxford University Press.

DAMAŠKA, Mirjan (1997). Evidence Law Adrift. New Haven: Yale University Press.

DAMAŠKA, Mirjan (2000). Las caras de la justicia y el poder del estado. Análisis comparado del proceso legal. (Trad.) Andrea Morales. Santiago: Editorial Jurídica de Chile.

Domínguez Águila, Ramón (1991). “Fraus omnia corrumpit. Notas sobre el fraude en el derecho civil". Revista de Derecho, $\mathrm{N}^{\circ} 189$, Concepción.

Ferreira da Silva, Carlos (2005). "Relações entre as partes, os juízes e os advogados no processo civil português", en Marcel Storme y Cipriano Gómez (coords.). XII Congreso Mundial de Derecho Procesal., UNAM, vol. III.

Fuller, Lon (1978). "The Forms and Limits of Adjudication”. Harvard Law Review, vol. 92. Cambrigde.

Gandulfo Ramírez, Eduardo (2009). "Sobre preclusiones procesales en el derecho chileno en tiempo de reformas. Ensayo de una teoría general desde un enfoque valorativo jurídico". Ius et Praxis. vol. 15, $\mathrm{N}^{\mathrm{O}} 1$, Talca.

González Coulon, María de los Ángeles. (2013). La carga dinámica de la prueba y sus límites. Santiago: Thomson Reuters. 
Gorigoitía Авотт, Felipe (2013). "Irregularidad, invalidez e ineficacia en el contexto de la nulidad procesal". Revista de Derecho, vol. 20, No 1, Coquimbo.

Gorigoitía Авотt, Felipe (2008). "La buena fe en el proceso civil chileno". Nomos. Revista de Derecho, No 2, Viña del Mar.

Guzmán Brito, Alejandro (2002). "La buena fe en el Código Civil de Chile". Revista Chilena de Derecho. vol. 29, No 1, Santiago.

Hernández Basualto, Héctor (2010). "La estafa triangular en el derecho penal chileno, en especial la estafa procesal". Revista de Derecho, vol. XXIII, $\mathrm{N}^{\circ} 1$, Valdivia.

Hunter Ampuero, Iván (2010), “Iura novit curia en la jurisprudencia civil chilena”. Revista de Derecho, vol. XxıII, No 2, Valdivia.

Hunter Ampuero, Iván (2008). "No hay buena fe sin interés: La buena fe procesal y los deberes de veracidad, completitud y colaboración”. Revista de Derecho, vol. XXI, $\mathrm{N}^{\mathrm{O}} 2$, Valdivia.

Jolowicz, John (2008). "ADR and the Role of Civil Litigation”. in Liber Amicorum. Mélanges dédiés à la mémoire du Doyen Jacques Héron. Paris: L.G.D.J.

Irureta Uriarte, Pedro (2011). "Vigencia del principio de la buena fe en el derecho del trabajo chileno". Ius et Praxis. vol. 17, $\mathrm{N}^{\circ} 2$, Talca.

Larroucau García, María Matilde (2010). "La buena fe procesal y el deber de colaboración de las partes en los procedimientos laborales". Revista Chilena de Derecho del Trabajo y de la Seguridad Social. vol. 1, N 1. Santiago.

302 LARroucau, Jorge e Ignacio Rostión (2013). "Del juicio de precario", en Rodrigo Barcia Lehmann (compilador), Fundamento de derechos reales en el Derecho chileno. Santiago: Thompson Reuters.

Larroucau Torres, Jorge (2012a). "Hacia un estándar de prueba civil”. Revista Chilena de Derecho. vol. 39, No 3, Santiago.

Larroucau Torres, Jorge (2012b). "Por un estándar amplio de admisibilidad de pruebas en la justicia civil”. Actas del Congreso Internacional de Derecho. En homenaje al Centenario de la Escuela de Derecho de la Universidad de Valparaíso. Valparaíso: EDEVAL, tomo IV.

LARroucau Torres, Jorge (2012c). "La opción de responsabilidad civil como un acertijo procesal”, en Fabián Elorriaga (coord.), Estudios de Derecho Civil VII. Santiago de Chile: Thomson Reuters.

MackaAy, Ejan (2012). "Good Faith in Civil Law Systems. A Legal-Economic Analysis”. Revista Chilena de Derecho, N 18, Santiago.

Micheli, Gian Antonio (1961). La carga de la prueba. (Trad.) Santiago Santis Melendo. Buenos Aires: Ediciones Jurídicas Europa-América.

Monteleone, Girolamo (2009). "Intorno al concetto di verità 'materiale' o 'oggetiva' nel processo civile”. Reiistra di Diritto Processuale, vol. LXIV, Padova.

Monteleone, Girolamo (2007). "Preclusiones y debido proceso. Dos conceptos incompatibles", (trad.) Eugenia Ariano Deho, en Andrés DE LA Oliva y Diego Palomo (coords.), Proceso civil. Hacia una nueva justicia civil. Santiago: Editorial Jurídica de Chile. 
Montero Aroca, Juan (2006). "Sobre el mito autoritario de la 'buena fe procesal"'. Proceso civil e ideología. Un prefacio, una sentencia, dos cartas y quince ensayos. Valencia: Tirant lo Blanch.

Murray, Peter \& Rolf Stürner (2004). German Civil Justice. Durham, North Carolina: Carolina Academic Press.

Omura, Masahiko (1998). "A Comparative Analysis of Trial Preparation: Some Aspects of the New Japanese Code of Civil Procedure", in Toward Comparative Law in the 21st Century. The 50th anniversary of the Institute of Comparative Law in Japan. Tokyo: Chuo University Press.

Orellana, Fernando y Álvaro Pérez Ragone (2008). "Radiografía de la rebeldía en el proceso civil. Tópicos hacia una adecuada regulación en la nueva justicia civil". Ius et Praxis, vol. 13, No 2. Talca.

Pacheco Valderrama, Christian (1995). El fraude procesal. Tesis de licenciatura: Concepción: Universidad de Concepción.

Palomo Vélez, Diego (2008). La oralidad en el proceso civil. El nuevo modelo español. Santiago: Librotecnia.

Pérez Ragone, Álvaro (2005). "La reforma del proceso civil alemán 2002. Segunda parte: El procedimiento de primera instancia”. Revista Peruana de Derecho Procesal, vol. viII, Lima.

Pérez Ragone, Álvaro (2007). "Perspectivas en la cooperación judicial probatoria comunitaria: Diligencias de transfrontera dentro de la Unión Europea", en Alejandro Romero (coord.). Estudios de derecho en homenaje a Raúl Tavolari Oliveros. Santiago: Editorial LexisNexis.

Picó i Junoy, Joan (2013). El principio de la buena fe procesal. $2^{\mathrm{a}}$ ed., Barcelona: Bosch Editor.

Picó I Junoy, Joan (2006). “El debido proceso 'leal'. Reflexiones en torno al fundamento constitucional del principio de la buena fe procesal". Revista Peruana de Derecho Procesal. vol. Ix, Lima.

Porat, Ariel \& Alex SteIn (2001). Tort Liability under Uncertainty. Oxford: Oxford University Press.

Romero Seguel, Alejandro (2003). "El principio de buena fe procesal y su desarrollo en la jurisprudencia, a la luz de la doctrina de los actos propios". Revista Chilena de Derecho. vol. 30, No 1, Santiago.

Romero Seguel, Alejandro (2000). "La caducidad por incumplimiento de cargas procesales". Revista Chilena de Derecho, vol. 27, No 2, Santiago.

Sentís Melendo, Santiago (1964). "Desarrollo del proceso. Deberes del juez y cargas de las partes”. Revista de Derecho Procesal, vol. IV. Buenos Aires.

STÜRnER, Rolf (2008). "La obtención de información probatoria en el proceso civil”. (Trad.) Álvaro Pérez Ragone. Revista de Derecho, $\mathrm{N}^{\mathrm{O}} \mathrm{xxx}$, Valaparaíso.

STÜRner, Rolf (2007). "Derecho procesal y culturas jurídicas”. (Trad.) Álvaro Pérez Ragone. Ius et Praxis, 13, No 1, Talca.

STÜRnER, Rolf (2010). La aclaración judicial en el proceso civil. (Trad.) Rodrigo Kaufmann. Tesis de Licenciatura. Santiago: Universidad de Chile. 
TARuffo, Michele (2009). "Elementos para una definición de 'abuso del proceso"”. Páginas de justicia civil. Madrid-Barcelona-Buenos Aires: Marcial Pons,.

TARUfFo, Michele (2006). "Dimensiones transculturales de la justicia civil", Sobre las fronteras. Escritos sobre la justicia civil. (trad.) Beatriz Quintero. Bogotá: Temis.

TARUfFo, Michele (ed.) (1999). Abuse of Procedural Rights: Comparative Standards of Procedural Fairness. Hague-London-Boston: Kluwer Law International.

TARuffo, Michele (2002). La prueba de los hechos. (Trad.) Jordi Ferrer, Madrid: Trotta.

Tavolari Goycoolea, Pía (2004). El abuso en el proceso. Santiago: Ediciones Jurídicas Congreso.

Tavolari Oliveros, Raúl (2002). "Abusos en el proceso". Revista Iberoamericana de Derecho Procesal, $\mathrm{N}^{\circ}$ 1, Buenos Aires.

Twining, William (2006). Rethinking Evidence. Exploratory Essays. $2^{\text {a }}$ ed. Cambrigde: Cambridge University Press.

Walker Silva, Nathalie (2011). "Daños causados por divulgación de la verdad". Revista Chilena de Derecho y Ciencia Política. vol. 2, No 2, Temuco.

\section{Normas citadas}

304 "Anteproyecto de Código Procesal Civil". Revista de Estudios de la Justicia, No 8, Santiago, Universidad de Chile, 2006.

Civil Procedure Rules inglesas (1998).

Code de Procédure Civil francés (1978).

Codice di Procedura Civile italiano (1942).

Código de Ética, Santiago, Colegio de Abogados de Chile, (2011).

Código de Processo Civil brasileño (1973).

Código de Processo Civil portugués (2013).

Código de Processo Civil portugués (1961/1995-96).

Código General del Proceso de Colombia (2012).

Código General del Proceso uruguayo (1989).

Código Procesal Civil japonés (1996).

Código Procesal Civil peruano (1993).

Código Procesal Civil Modelo para Iberoamérica (1988).

Comissão de Juristas Responsável pela Elaboração de Anteprojeto de Código de Processo Civil brasileño (2010).

Federal Rules of Civil Procedure estadounidenses (1938/2007).

Ley de Enjuiciamiento Civil española (2000).

Ley No 19.496, Normas sobre Protección de los Derechos de los Consumidores. Diario Oficial, 7 de marzo de 1997. 
Principios UNIDROIT (2004).

Proyecto de Código Modelo de Procesos Administrativos -Judicial y Extrajudicial- para Iberoamérica (2012).

Proyecto de Código Procesal Civil de 2009 (Boletín No 6567-07).

Proyecto de Código Procesal Civil de 2012 (Boletín No 8197-07).

Repertorio de Legislación y Jurisprudencia Chilenas. Código de Procedimiento Civil, $4^{\mathrm{a}}$ ed. Santiago, Editorial Jurídica de Chile, 2010, vol. III.

Zivilprozessordnung alemán (2002), traducción de Juan Carlos Ortiz y Álvaro Pérez Ragone, Konrad Adenauer Stiftung, Programa Estado de Derecho para Sudamérica, Montevideo, 2006.

\section{Jurisprudencia citada}

Vega con Transportes Alfa Limitada (1993): Corte de Apelaciones de Santiago, 7 de junio de 1993, Revista de Derecho y Jurisprudencia, tomo 90, sección 3 $3^{\mathrm{a}}, 103$, cons. $1^{\circ}$ (redacción del abogado integrante Luis Ribalta).

Villanueva con Sanhueza (2001): Corte Suprema, 9 de mayo de 2001, Microjuris MJCH_MJJ7138, cons. $3^{\circ}$ (redacción del abogado integrante René Abeliuk).

Corte de Apelaciones de Concepción, 23 de agosto de 2002, rol N $\mathrm{N}^{\circ} 79-2002$, vLex: VLEX-32024484, cons. $10^{\circ}$ (redacción del abogado integrante Mario Romero Guggisberg).

Opazo con Brown y otro (2007): Juzgado de Letras de San Vicente de Tagua Tagua, 22 de mayo de 2007, rol $\mathrm{N}^{\circ} 43829$, LegalPublishing $\mathrm{N}^{\circ} 42866$, cons. $16^{\circ}$ (redacción de la jueza Carolina Garrido).

Inmobiliaria Alameda de Antofagasta con Vergara (2007): Corte Suprema, 30 de mayo de 2007, rol No 4680-2005, Microjuris, $N^{\circ}$ MJJ10201, cons. $10^{\circ}$.

Alarcón y otros con Empresa Constructora Emasil S.A. (2008): Corte Suprema, 25 de septiembre de 2008, rol N 59-2007, vLex: VLEX-332793842. 